\title{
EchoGéo
}

$26 \mid 2013$

Varia

\section{Patrimonialisation et greffes culturelles sur des friches issues de l'industrie minière}

Regards croisés sur l'ancien bassin minier du Nord-Pas de Calais (France) et la vallée de l'Emscher (Allemagne)

\section{Bruno Lusso}

\section{OpenEdition}

\section{Journals}

Édition électronique

URL : https://journals.openedition.org/echogeo/13645

DOI : $10.4000 /$ echogeo. 13645

ISSN : 1963-1197

Éditeur

Pôle de recherche pour l'organisation et la diffusion de l'information géographique (CNRS UMR 8586)

Référence électronique

Bruno Lusso, "Patrimonialisation et greffes culturelles sur des friches issues de l'industrie minière ", EchoGéo [En ligne], 26 | 2013, mis en ligne le 19 décembre 2013, consulté le 21 septembre 2021. URL http://journals.openedition.org/echogeo/13645; DOI : https://doi.org/10.4000/echogeo.13645

Ce document a été généré automatiquement le 21 septembre 2021.

EchoGéo est mis à disposition selon les termes de la licence Creative Commons Attribution - Pas d'Utilisation Commerciale - Pas de Modification 4.0 International (CC BY-NC-ND) 


\section{Patrimonialisation et greffes culturelles sur des friches issues de l'industrie minière}

Regards croisés sur l'ancien bassin minier du Nord-Pas de Calais (France) et la vallée de l'Emscher (Allemagne)

Bruno Lusso

\section{Introduction}

1 Cet article a pour objectif d'analyser les modalités de patrimonialisation et de transformation des infrastructures industrielles liées à l'exploitation charbonnière en équipements culturels dans les bassins miniers du Nord-Pas de Calais (nord de la France) et de la Ruhr (ouest de l'Allemagne). Ces deux bassins ont pour point commun d'avoir développé à partir du XVIII siècle la production charbonnière, métallurgique et sidérurgique, et connu un déclin industriel et économique accéléré à partir des années 1960. L'extraction charbonnière des bassins miniers du Nord-Pas de Calais et de la Ruhr s'effectue dans des conditions d'exploitation difficiles qui rendent la production peu rentable par rapport aux gisements miniers états-uniens, australiens ou russes. C'est dans ce contexte très difficile qu'est envisagée en France, par le Plan Jeanneney de 1963, la disparition progressive des mines devenue effective en 1990 pour le bassin minier du Nord-Pas de Calais. Dans la Ruhr, la fin des années 1960 marque le début d'une inexorable récession de la production charbonnière qui devrait définitivement cesser en 2018. 
Illustration 1 - L'ancien bassin minier du Nord-Pas de Calais

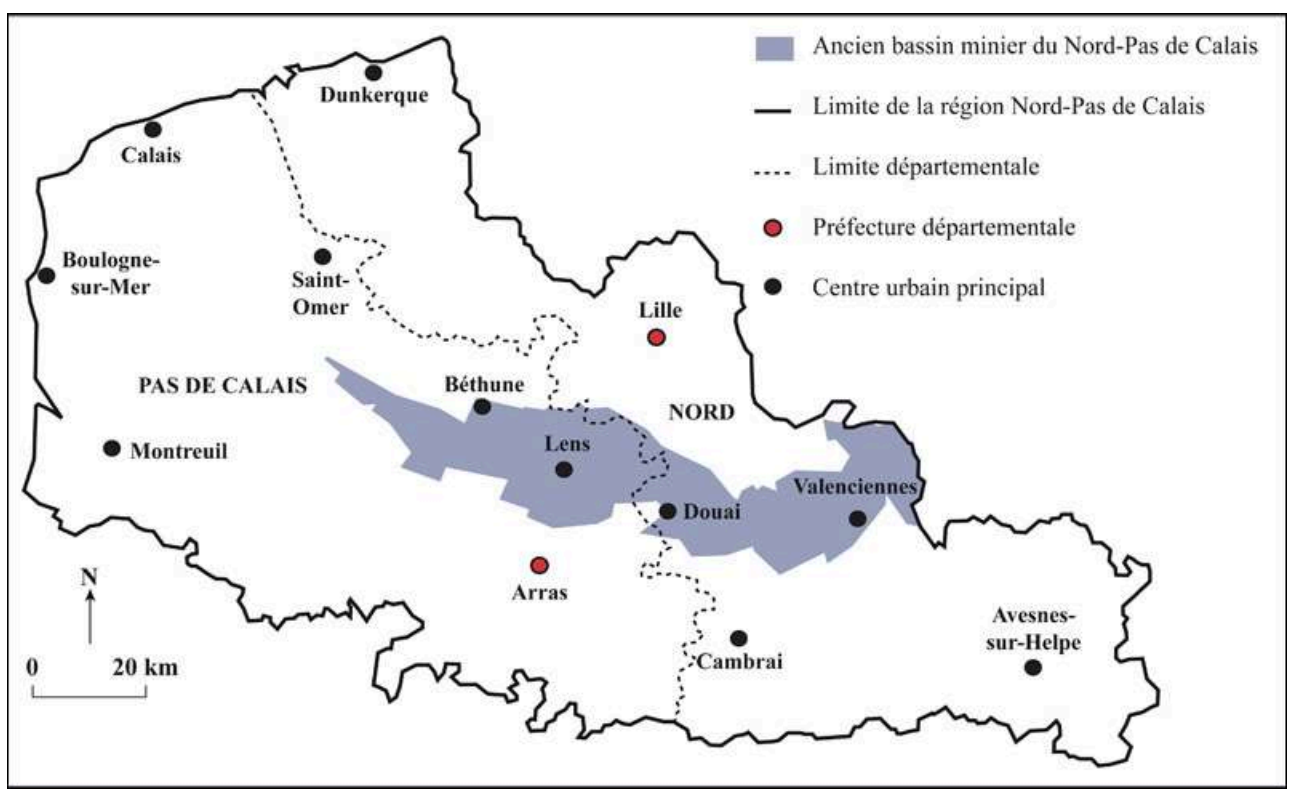

Source : www.usinenouvelle.com/article/le-bassin-minier-du-nord-pas-de-calais-au-patrimoinemondialdel'unesco ; réalisation : B. Lusso, 2013.

Illustration 2 - La Ruhr et la vallée de l'Emscher

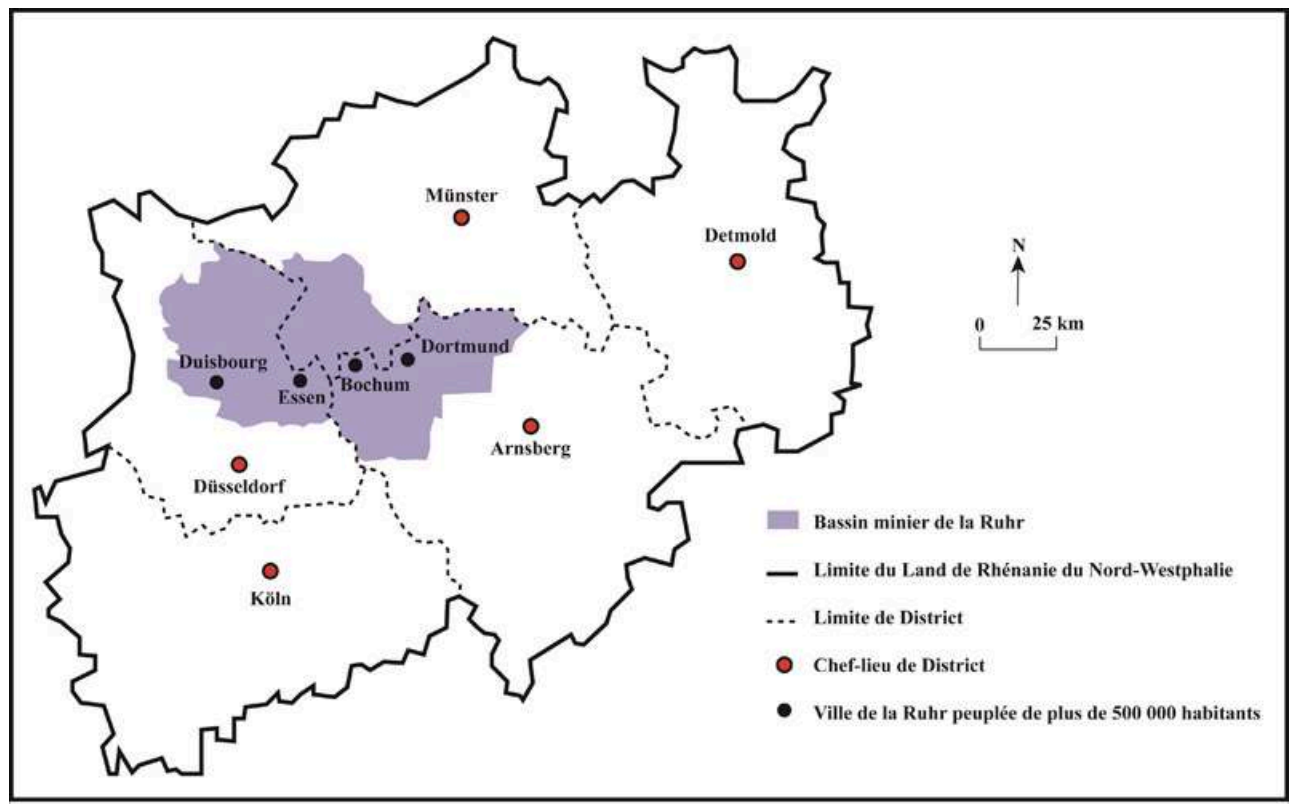

Source : L'IBA Emscher Park : Une démarche innovante de réhabilitation industrielle et urbaine, Recherche et prospective, 2008 ; réalisation : B. Lusso, 2013.

2 Ces deux bassins industriels développent alors, selon les termes des acteurs participant à l'aménagement de ces territoires, «l'image répulsive de pays noir " (Ganser, 1996; Bertram et Delmer, 2012), dans la mesure où ils manquent clairement de qualités urbaines et paysagères (Deshaies, 2007). Ces régions, qui ne comptent pas de ville capitale, se sont urbanisées sur les noyaux villageois et autour d'une industrialisation qui s'est développée sans contrainte, colonisant tout l'espace et laissant aujourd'hui derrière elle des milliers d'hectares de friches. En France, selon l'EPF (Établissement 
Public Foncier) du Nord-Pas de Calais, une friche industrielle est « un espace, bâti ou non, qui a participé ou participe encore marginalement à une activité industrielle et dont l'état de dégradation est tel que tout nouvel usage du sol ou du bâti n'est possible qu'après une remise en état notable ». En Allemagne, les friches industrielles désignent « des espaces abandonnés qui ont été utilisés pour la production mais sur lesquels plus aucune activité économique ne peut désormais prendre place» (Güthling, 2009). La situation est particulièrement dramatique dans la vallée de l'Emscher, région située au nord de la Ruhr et totalement dénuée de centralités, qui abrite un très grand nombre de sites industriels contaminés et la rivière la plus polluée d'Europe occidentale au début des années 1990. Avec $50 \%$ des friches industrielles de France - dont la majeure partie localisée dans le bassin minier - au début des années 1990, la situation de la région Nord-Pas de Calais n'est guère meilleure. Les friches industrielles peuvent être considérées comme une synthèse des problèmes de pollution et de déstructuration territoriale-véhiculant ainsi une image profondément négative pour les territoires concernés.

3 La question du recyclage des friches industrielles devient, au début des années 1990, un enjeu fondamental pour les deux vieilles régions industrielles (Joly, 2001). La patrimonialisation désigne un processus par lequel un espace, un bien ou une pratique est reconnu par la société comme un objet digne de restauration, d'entretien et de conservation. À la différence du patrimoine religieux, civil, militaire ou naturel, le patrimoine industriel a fait l'objet d'une reconnaissance beaucoup plus tardive (Edelblutte, 2008). Les recherches menées sur le patrimoine industriel en France (Daumas, 1980 ; Andrieux, 1992 ; Belhoste et Smith, 1997 ; De Roux, 2000) comme en Allemagne (Becher et Becher, 1970 ; Militz et Rudolph, 1984 ; Krins, Goer et Schmidt, 1991 ; Schwarz, 2001 ; Oevermann, 2012) sont souvent très générales et/ou illustratives. Mais la réactivation des ressources patrimoniales, matérielles ou immatérielles, y compris dans les villes n'ayant pas un patrimoine monumental, est devenue un véritable enjeu en termes de développement touristique (Van der Bord, Costa et Gotti, 1996 ; Gravari-Barbas, 2005) et de marketing urbain (Ingallina et Park, 2005). La mise en patrimoine des anciennes installations industrielles revêt alors un caractère purement cosmétique et dilatoire dans des régions dévastées par les dynamiques spatiales du capitalisme contemporain (Hudson et Sadler, 1989 ; Harvey, 1989).

4 Le redéploiement économique de ces sites industriels patrimonialisés devient alors une question essentielle. Sur ces friches peuvent émerger de nouvelles fonctionnalités à caractère culturel contribuant à la fabrique du lieu (Fagnoni, 2009) et à un processus de reterritorialisation de ces espaces abandonnés par les activités économiques (Lucchini, 2012). À partir des années 1990 , la problématique du rôle de la culture dans le développement économique a profondément évolué. La culture, originellement considérée comme un luxe subordonné à une croissance urbaine forte (Lusso, 2008), est devenue un outil de développement territorial. La culture sert désormais de levier à nombre de projets de requalification urbaine (Andres et Ambrosino, 2008). Considérée comme motrice dans les processus de transformation physique, économique et sociale des espaces déprimés, la régénération culturelle (Bianchini et Parkinson, 1993) s'est imposée dans l'esprit des pouvoirs publics comme une des stratégies de développement urbain les plus efficaces, notamment sur les friches et anciens quartiers industriels. Les modalités de reconversion des vieilles régions industrielles et de recyclage des friches industrielles est une question qui a été largement traitée à l'échelle des bassins miniers 
du Nord-Pas de Calais (Baudelle, 1995 ; Joly, 2001) et de la Ruhr (Holz, 1988 ; Joly, 2001 ; Kunzmann, 1996). Ces travaux ont mis en exergue des différences entre les deux bassins miniers en termes d'institutions, de dispositifs d'aménagement, de modes de financement, de modalités de reconversion paysagère et économique des sites industriels et de résultats en matière de développement territorial. L'objectif de cet article est d'analyser l'efficience des politiques patrimoniales et culturelles menées sur les friches industrielles, en confrontant l'exemple très connu et médiatique de la vallée de l'Emscher à celui du Nord-Pas de Calais. En s'appuyant sur les politiques mises en place et les projets concrétisés dans les deux bassins miniers, notre propos se divisera en trois parties :

- Les étapes de la patrimonialisation des installations minières dans les bassins du Nord-Pas de Calais et de la vallée de l'Emscher;

- Les modalités de la transformation urbaine et architecturale de ces infrastructures industrielles;

- Les activités culturelles et artistiques développées dans le cadre de ces politiques de reconversion.

Dans cet article, nous nous intéresserons plus spécifiquement aux friches minières (fosses, lavoirs, usines à boulets, terrils) et aux industries liées à l'activité charbonnière (cokeries, aciéries, usines métallurgiques). Pour ce faire, il a été nécessaire d'identifier dans un premier temps l'ensemble des équipements culturels implantés dans les deux bassins miniers. Une liste non exhaustive a été établie à partir des annuaires téléphoniques et d'une géolocalisation des sites miniers sur Google Earth. Ce travail préalable a permis d'élaborer un questionnaire envoyé à une vingtaine d'équipements culturels dans les deux bassins miniers. Celui-ci posait les questions de la réhabilitation de l'infrastructure, des publics accueillis, des activités mises en place par les structures, $\mathrm{du}$ budget et des modes de financement de l'institution. Cette connaissance des principales structures culturelles créées sur d'anciens sites industriels a été utile lors de la dizaine d'entretiens semi-directifs réalisés auprès des établissements chargés du recyclage du foncier (EPF Nord-Pas de Calais), des associations de protection et de défense du patrimoine (Mission Bassin Minier Uni), des directions à l'économie des collectivités territoriales (municipalités, Association régionale de la Ruhr, Conseil Régional du Nord-Pas de Calais) et de chercheurs allemands francophones. Ces entretiens avec différents acteurs ont permis de reconstituer une chronologie globale des politiques de reconversion menées dans les deux bassins miniers, ainsi que des mesures développées en faveur du recyclage des friches industrielles en équipements culturels. La lecture des plans d'aménagement et de la littérature portant sur les thématiques de reconversion des bassins miniers de la Ruhr et du Nord-Pas de Calais a complété ces informations.

\section{Deux approches différentes du recyclage des friches industrielles et de la protection du patrimoine minier}

6 La reconnaissance de la qualité du patrimoine industriel a été plus rapide dans les pays qui ont connu une désindustrialisation précoce. C'est le cas des États-Unis et du Royaume-Uni qui ont instauré durant l'entre-deux guerres les premières mesures visant à étudier et à réhabiliter leur patrimoine industriel (Delony, 1992). Dès 1939, le National Trust anglais développe des mesures de préservation du patrimoine industriel 
à l'image du Quarry Bank Mill de Styal, une filature textile reconvertie en musée du coton (Andrieux, 1992). D'après R. Leboutte (1997), cette valorisation précoce du patrimoine industriel est en partie liée à la place que tient le travail dans la société. « Si dans les pays latins à dominante catholique (France, Italie, Espagne) la valeur travail est moins reconnue, la réussite professionnelle est en revanche un signe de bienveillance divine dans les pays de la Réforme, expliquant une valorisation plus forte de l'histoire industrielle dans des pays comme le Royaume-Uni, la Suède ou certaines régions de l'Allemagne » (Edelblutte, 2008). L'objectif de cette première partie est donc de retracer de manière chronologique les acteurs, outils et modes de financement de la reconversion des friches industrielles dans les bassins miniers de la Ruhr et du NordPas de Calais. Deux périodes principales se distinguent: une première allant des années 1950 à 1990 marquée par les premières mesures en direction du recyclage des friches minières et une deuxième à partir des années 1990 qui constitue un approfondissement de ces politiques avec la création de nouveaux outils utiles à la reconversion de ces sites industriels. Ce rapide descriptif historique permettra de dresser un bilan de la protection des friches industrielles dans la vallée de l'Emscher et le bassin minier du Nord-Pas de Calais.

\section{Premières mesures de protection du patrimoine minier dans la Ruhr versus destructions massives dans le Nord-Pas de Calais (1950-1990)}

7 Dans les deux bassins houillers, les friches minières occupent de vastes surfaces plusieurs dizaines d'hectares en moyenne - situées le plus souvent en périphérie des villes ou des centres urbains. Leur localisation, dans la continuité ou au sein même du tissu urbain, entraîne généralement de véritables coupures urbaines qui constituent un frein au développement de ces conurbations industrielles. Dans l'attente d'un éventuel rachat ou d'une réhabilitation, les bâtiments sont sécurisés par des clôtures électriques ou surveillés par des gardiens. Laissées à l'abandon par leurs anciens propriétaires, ces friches industrielles se dégradent au fil des années créant ainsi une véritable pollution visuelle. Leur requalification devient pour les collectivités autant un objectif qu'un problème en raison de la nécessaire dépollution de ces sites marqués par des décennies d'activité industrielle. Deux possibilités s'offrent donc aux aménageurs :

- La première consiste en la démolition totale de la friche pour reconstituer un site vierge peu contraignant quant à son urbanisation future.

- La seconde vise la protection du patrimoine industriel et la réutilisation des bâtiments existants pour de nouvelles activités, solution qui pose cependant la question de la réadaptation du bâtiment à de nouveaux usages.

8 Dans la Ruhr, les premières mesures de protection du patrimoine industriel apparaissent au début des années 1980 (Masboungi, 2000) et font suite à un ensemble de protestations émanant de la société civile. En 1969, un groupe d'artistes choqués par le projet de destruction du complexe minier Zollern II-IV à Dortmund décide d'occuper la salle des machines pour en empêcher son démantèlement. Parmi eux, les photographes Bernd et Hilla Becher qui entament dès la fin des années 1970 un véritable travail d'entomologistes du patrimoine industriel (Becher et Becher, 1970 ; Becher et Becher, 1985). Ils constituent un catalogue précis d'images d'usines et d'infrastructures industrielles abandonnées contribuant ainsi à renverser la vision qu'ont les habitants, 
les décideurs politiques et les aménageurs de leurs paysages industriels. Désormais, mines, lavoirs, aciéries, cokeries et terrils revêtent aux yeux des populations un caractère identitaire (Soyez, 1999).

Disposant d'importantes prérogatives en matière d'aménagement du territoire, les municipalités mettent en place toute une série de mesures visant à protéger et à reconvertir ces sites industriels désaffectés. En effet, le premier syndical intercommunal d'Allemagne, l'Association du district minier de la Ruhr (SVR, Siedlungsverband Ruhrkohlenbezirk) a été créé en 1920. Celui-ci a lancé dès 1951 un schéma de reconquête des friches industrielles complété à la fin des années 1960 par un programme de création d'équipements de loisirs. En 1979, le SVR devient une association de communes du bassin de la Ruhr (KVR, Kommunalverband Ruhrgebiet) qui assure, sans pour autant avoir une stratégie foncière propre, la protection de l'environnement, l'entretien des paysages, la reconquête des friches industrielles et la mise en place d'infrastructures de loisirs. Ainsi, dès les années 1980, la question du traitement paysager des friches minières, qui s'appuie sur la reconnaissance du patrimoine industriel et le développement de bases de loisirs, fait l'objet d'une stratégie régionale dotée de moyens d'actions conséquents provenant notamment des villes et du Land de Rhénanie du Nord-Westphalie. La réhabilitation en 1977 des anciens ateliers ferroviaires de Bochum-Dalhausen en un musée consacré aux chemins de fer ou la création en 1984 à Hamm du Maximilian Park, un jardin public implanté sur le site d'une mine et d'un lavoir désaffectés, témoigne de ces politiques.

10 En revanche, dans le bassin minier du Nord-Pas de Calais, le patrimoine industriel n'est pas encore perçu comme un bien culturel valorisable par l'État, acteur quasiment exclusif des premières politiques de reconversion du territoire (Joly, 2001). En effet, l'accent est mis sur la revitalisation économique à court terme, l'emploi et la réalisation d'équipements publics, comme le souligne le lancement d'un programme d'aménagement spécifique aux principaux centres urbains du bassin minier. Il faut reconnaître que le Nord-Pas de Calais est confronté dans les années 1970 à une crise industrielle généralisée qui touche aussi d'autres fleurons régionaux comme l'industrie textile (métropole lilloise) et la sidérurgie (Valenciennes et Maubeuge principalement). Des questions comme le cadre de vie ou le patrimoine sont alors considérées comme secondaires. Les installations minières sont donc systématiquement rasées par les Houillères du Bassin du Nord-Pas de Calais afin de libérer l'espace pour de nouvelles activités. Les terrils sont exploités à partir des années 1970 pour mener à bien les chantiers de reconversion économique (aménagement de zones industrielles, de routes ou d'autoroutes, et de la LGV Nord). Les lois de décentralisation de 1982 instituent une concertation entre l'État et les collectivités territoriales, notamment dans le cadre des plans État-Région. Dès 1984, le bassin minier fait l'objet d'un plan qui vise alors le traitement paysager des friches industrielles considérées comme un obstacle à la reconversion régionale. Ainsi, 1500 hectares de friches font l'objet d'une requalification et d'un verdissement en vue d'une réutilisation future (parcs de la Lawe à Bruay-la-Buissière, de la Clarence à Divion, de la Loisne à Barlin, de Wingles et de la Glissoire à Lens-Avion). C'est au même moment qu'apparaissent les premiers fonds pour la résorption des friches minières comme les crédits du Groupe Interministériel pour la Restructuration des Zones Minières (GIRZOM) mis en place à partir de 1982.

11 Pourtant la dimension patrimoniale n'est pas complètement ignorée. Au début des années 1970, les Houillères du Bassin du Nord-Pas de Calais projettent la création d'un 
musée retraçant l'histoire régionale de la mine. C'est le site de l'ancienne fosse Delloye à Lewarde, en instance de démantèlement, qui est retenu pour accueillir le futur équipement culturel. Les Houillères ont justifié leur choix par la localisation du site au centre $\mathrm{du}$ bassin minier et à proximité du réseau autoroutier, mais aussi pour son architecture emblématique de la mine française de l'entre deux-guerres. Le Centre Historique Minier de Lewarde qui ouvre ses portes en 1984, initie alors une dynamique de reconnaissance du patrimoine industriel dans la région Nord-Pas de Calais. Celle-ci s'amplifie avec le lancement la même année à Lille de l'Association des Régions Européennes de Tradition Industrielle (Ernecq, 1998). Des voyages dans la Ruhr sont donc organisés par le Conseil Régional du Nord-Pas de Calais. Les pratiques allemandes interpellent les acteurs régionaux et les populations qui comprennent la valeur culturelle et sociale de leur patrimoine minier. Des associations locales composées majoritairement d'anciens mineurs se créent pour sauver de la destruction un chevalet, des bâtiments ou des sites miniers complets. Mais ces tentatives échouent le plus souvent, principalement pour des raisons financières. Ainsi, le projet de protection de la mine Barrois à Pecquencourt, appelée la «fosse de l'an 2000 ", ne tient pas face au coût exorbitant de l'entretien de l'édifice, si bien que la municipalité finit par accepter le démantèlement du site en 1991. En revanche, d'autres projets aboutissent et permettent de sauver certains chevalements (association du 8 à Evin-Malmaison, protection du chevalet de la fosse 9 de l'Escarpelle à Roost-Warendin sur arrêté municipal) ou des ensembles complets (fosses $9 / 9$ bis d'Oignies et 11/19 de Loos-enGohelle).

\section{Une accélération du recyclage des friches minières et des mesures patrimoniales dans les deux bassins miniers (depuis 1990)}

12 Le recyclage et la patrimonialisation des friches industrielles dans le bassin minier du Nord-Pas de Calais et la vallée de l'Emscher connaissent à partir de 1990 un véritable coup d'accélérateur en raison notamment de la mise en place de structures chargées d'assurer la conversion des sites miniers. En 1989, le Land de Rhénanie du NordWestphalie lance pour une durée de dix ans une IBA (Exposition internationale d'architecture) dans la vallée de l'Emscher. Cette opération médiatique vise, selon les mots de son directeur Charles Ganser, à attirer des architectes de renom et à susciter de grands projets innovants à partir de la réutilisation d'anciennes friches industrielles, dans l'espoir de provoquer une transformation structurelle de la région (Ganser, 1996). Rejetant l'idée de planification spatiale, l'IBA soutient uniquement des projets qui s'appuient sur la réutilisation des bâtiments existants, le patrimoine, l'écologie et la festivalisation de la culture. L'objectif de l'IBA est de réhabiliter les friches industrielles avec l'aide de paysagistes ou d'artistes pour leur donner un nouvel usage favorisant ainsi la diversité des fonctions, mais aussi la reconstitution d'un paysage et d'un cadre de vie agréable. Afin d'endiguer la consommation de sites vierges dans une région densément peuplée, l'IBA renforce les procédures existantes qui imposent aux communes souhaitant urbaniser de nouveaux terrains de prouver qu'aucun autre foncier situé en zone déjà urbanisée n'est disponible. Cependant, la reconquête des friches pose la question de la décontamination des sites. Ainsi, dans les cas de coûts de décontamination trop élevés, l'IBA préfère ne pas utiliser les sols et attendre que la nature les retraite avec le temps. Cette stratégie vise donc à préparer d'abord le 
territoire pour le rendre ensuite attractif. Une telle approche suppose l'acceptation d'un impact territorial différé.

Pour concrétiser les principes développés par l'IBA, une société de droit privé appartenant conjointement à l'État et au Land de Rhénanie du Nord-Westphalie, l'IBA Emscher Park, est créée en 1989. Celle-ci prévoit pour la fin de l'année 1999 la réalisation de 120 projets d'aménagement (création d'une trame verte, restauration écologique du système fluvial de l'Emscher, implantation de parcs technologiques, réhabilitation, rénovation et construction de logements, préservation des friches industrielles pour des fonctions culturelles et artistiques), ainsi que l'organisation d'un bon nombre d'événements festifs dans le périmètre des 17 communes de la vallée de l'Emscher. Une SARL d'une durée de vie limitée à 10 ans, IBA Gmbh, est créée par le Land pour mettre en œuvre ce programme. L'IBA est plutôt un promoteur d'idées. L'initiative et la maitrise d'ouvrage des projets restent du ressort de la commune concernée ou de sociétés d'aménagement commanditées par la commune elle-même. Un comité associe des représentants du Land, des villes concernées, du monde économique, des syndicats, des associations et des architectes. Pour assurer la réalisation de ces projets d'aménagement, le Fonds Foncier Régional (Grundstücksfond) créé en 1980, met à disposition des financements publics destinés à la reconversion des friches industrielles. Sa vocation est de remettre dans le circuit économique des terrains hors marché du fait des coûts de décontamination qui leur sont souvent associés. L'objectif visé est double : réhabiliter un paysage et un tissu urbain détruits par l'industrialisation et répondre à la pénurie de foncier disponible dans une région densément peuplée. Grâce à une dotation de 100 millions de marks par an (environ 50 millions d'euros), le fonds est intervenu sur 160 terrains, soit une surface de 2500 hectares. $40 \%$ d'entre eux ont pu être revendus pour accueillir de nouvelles activités ou ont été reconvertis en espaces verts. La gestion du fonds est confiée depuis 1979 à la LEG (Landesentwicklungsgesellschaft), une société immobilière et d'aménagement de droit privé, dont le Land détient la majorité du capital. Cette société gère les biens fonciers et immobiliers, et assure les services d'aménagement, de maîtrise d'ouvrage et de développement.

À la fin de l'IBA, le Land de Rhénanie du Nord-Westphalie a mis en place une structure, Die Regionallen, permettant à d'autres territoires de bénéficier d'un dispositif similaire qui s'appuie désormais sur des projets d'une durée de deux ans et financièrement moins bien dotés. Dans le cadre de l'IBA, le rôle du KVR a été renforcé, notamment par le développement de nouvelles compétences culturelles et économiques, mais surtout grâce à la gestion du parc paysager de la vallée de l'Emscher. En 2004, le KVR est devenu l'Association régionale de la Ruhr (RVR, Regionalverband Ruhr) avec des prérogatives élargies en matière de planification spatiale. Ainsi, en 2007, une stratégie a été mise en place par les 35 villes de la Ruhr, soit une population totale de 4,8 millions d'habitants, pour réaliser environ 300 projets reposant sur le développement durable, l'identité et les qualités architecturales et paysagères. Le financement de ces projets Konzept Ruhr est assuré par le biais d'un partenariat entre les pouvoirs publics et des investisseurs privés. C'est le cas de l'ancienne mine Ewald fermée en 2001 qui a fait l'objet d'une reconversion menée par la ville de Herten en partenariat avec une société immobilière, RAG Montan Immobilien $\mathrm{GmbH}$, pour y accueillir un parc technologique, une zone logistique et des activités culturelles. 
Dans le bassin minier du Nord-Pas de Calais, la contractualisation entre l'État et la Région Nord-Pas de Calais lancée dans les années 1980 a certes permis le recyclage de quelques friches industrielles localisées en tissu urbain ou présentant un intérêt spécifique, mais d'autres sites aux contraintes physiques et environnementales plus grandes n'ont pas trouvé preneur. Certaines friches minières sont donc restées durablement en dehors du marché foncier. Pour remédier à ce problème, l'Etablissement Public Foncier (EPF) Nord-Pas de Calais a été créé par l'État en 1990 sur demande des élus régionaux. Si l'EPF Nord-Pas de Calais a requalifié entre 1990 et 2000 environ 5000 hectares de friches industrielles, dont une grande partie dans le bassin minier, il est aussi devenu, grâce à la perception de la taxe spéciale d'équipement à partir de 1996, un opérateur foncier accompagnant les collectivités territoriales, par le biais de conventions, dans la maitrise du foncier et le recyclage des espaces industriels dégradés. Néanmoins, l'ensemble des actions de l'EPF s'effectue à l'échelle de la région Nord-Pas de Calais - et non à celle du seul bassin minier - et ne relève pas forcément de la protection du patrimoine minier. Elles visent davantage la reconversion économique et paysagère d'espaces industriels tombés en déshérence. Parallèlement, face à la surexploitation des terrils, l'association La Chaîne des Terrils est créée en 1989 pour favoriser leur protection et leur mise en valeur à des fins écologiques et récréatives. Au fil des contrats de plan État-Région successifs, la Chaîne des Terrils encourage notamment le verdissement des terrils et la transformation des anciens cavaliers miniers en chemins de randonnée. Au fil des années, la politique de traitement massif des stigmates et le pré-verdissement des sites industriels dans l'attente d'un usage futur a progressivement évolué vers une politique intégrée au service du renouvellement urbain, des grands projets économiques d'intérêt régional et de la trame verte et bleue (Joly, 2001).

\section{Des bilans contrastés en termes de protection des friches industrielles}

Cette approche différente de la reconversion des sites industriels a donc des retombées sur la protection du patrimoine minier. Dans le Nord-Pas de Calais, le bilan de la protection des installations minières est globalement très mince puisque sur plus de 250 chevalets, seulement 23 sont encore debout. Quatre sites miniers entiers ont été complètement restaurés (fosse Delloye à Lewarde, fosse 11/19 de Loos en Gohelle, fosse Arenberg à Wallers, fosse $9 / 9$ bis d'Oignies). Un certain nombre d'installations comme la fosse d'Anhiers sont encore visibles mais bien souvent à l'état de ruine, alors qu'aucun projet de reconversion n'est encore envisagé. La reconnaissance du patrimoine industriel n'empêche pas des destructions de bâtiments miniers comme le montre l'exemple du projet du Louvre-Lens. Implanté sur le site du 9 des mines de Lens partiellement détruit en 1983, la construction du musée a entraîné, au grand dam des associations locales de protection du patrimoine minier, la destruction des derniers bâtiments encore visibles. Ce bilan paraît globalement décevant, mais cache en réalité une grande diversité de bâtiments conservés sur les sites miniers du bassin. Ainsi, près de Béthune, la lampisterie de la fosse 6 d'Haillicourt est devenue une salle des fêtes. À Sallaumines, à proximité de Lens, les bains-douches, la lampisterie, le magasin, la salle de paye et le logement du garde du puits $5 / 12$ ont été conservés pour abriter les services techniques de la ville. Au final, rares sont les sites comme le puits $4 / 5$ de Méricourt fermé en 1988 à avoir été intégralement rasés. 


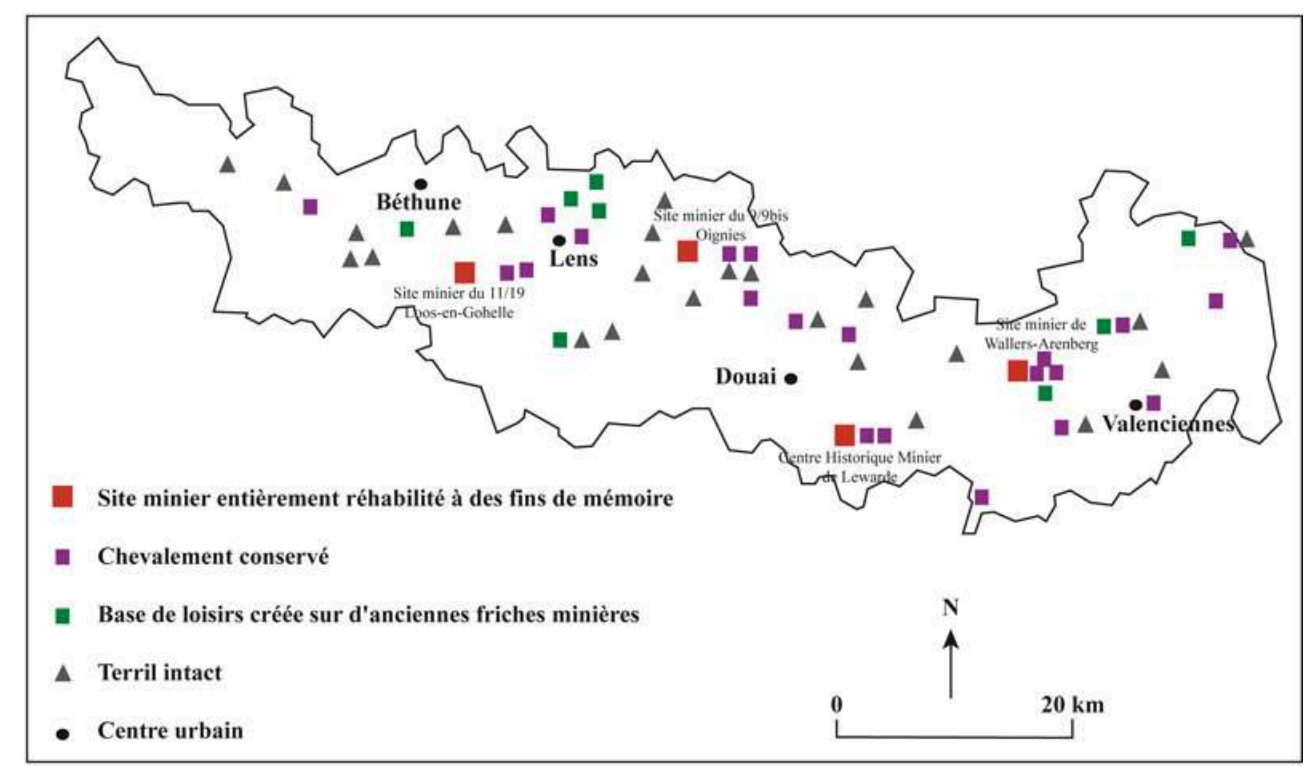

Source : Comité Régional du Tourisme, Mission Bassin Minier ; réalisation : B. Lusso, 2013.

Néanmoins, sans pour autant perdre son identité, l'ancien « pays noir » est devenu vert. Cette observation témoigne donc de la réussite de la reconversion écologique des sites miniers. Au total, en l'espace de 30 ans, plus de 8000 hectares de friches industrielles ont été reconquis pour accueillir des espaces verts, des bases des loisirs ou des réservoirs faunistiques. Environ 120 kilomètres de cavaliers miniers, ces anciennes voies ferrées minières, ont été transformés en itinéraires de randonnée. 200 terrils, dont 40 pré-verdis, sont encore visibles dans la région Nord-Pas de Calais. Les étangs d'affaissements miniers tels que la mare à Goriaux implantée au cœur de la forêt domaniale de Raismes-Saint-Amand-Wallers, sont devenus des réserves biologiques. Les collectivités territoriales ont même fait preuve de beaucoup de créativité dans le recyclage de leurs friches minières comme l'atteste la base de loisirs Loisinord à Noeuxles-Mines qui accueille une piste de ski artificielle installée depuis 1996 sur un ancien terril, une base nautique, un centre commercial et une discothèque. 


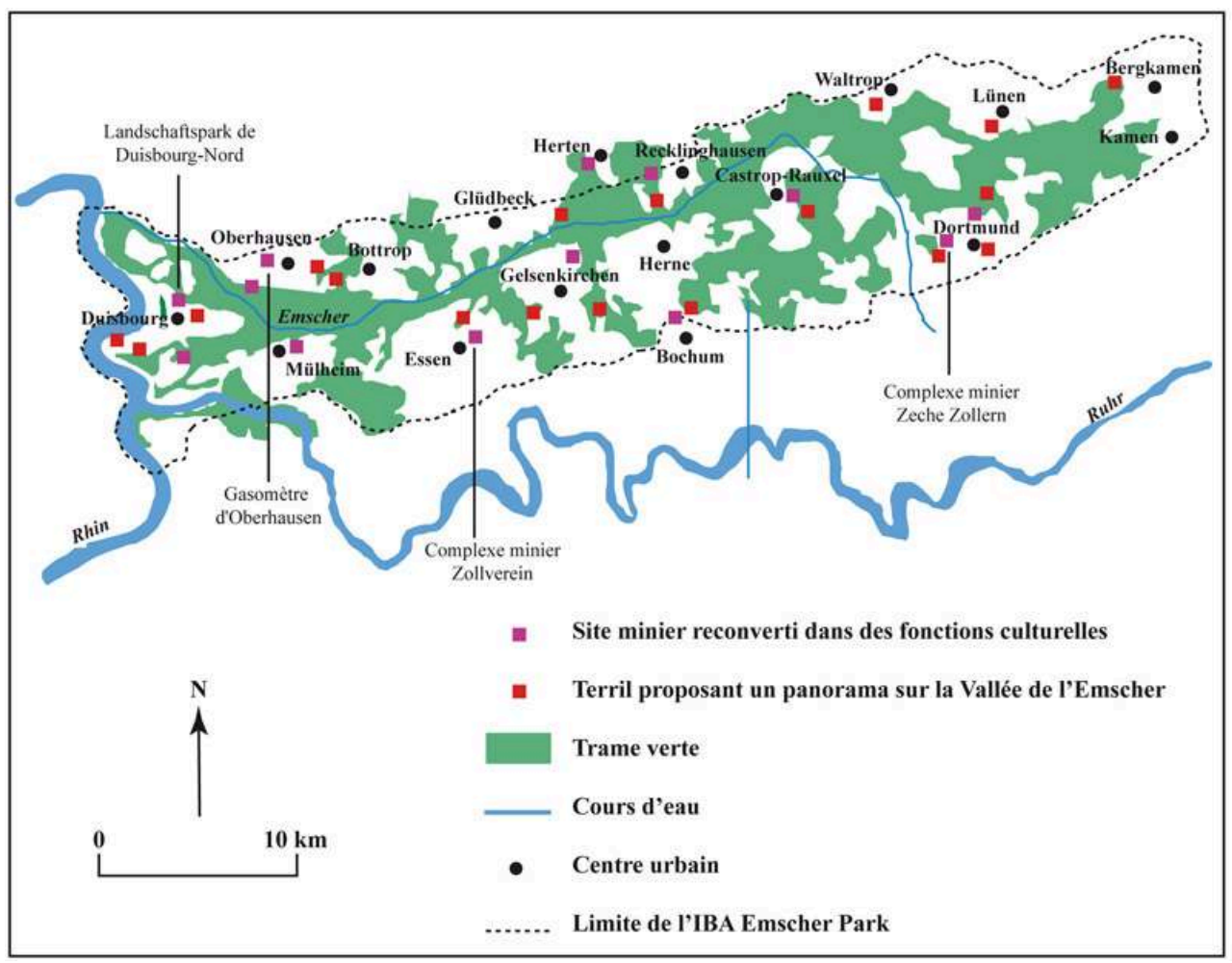

Source : IBA Emscher Park : Une démarche innovante de réhabilitation industrielle et urbaine, Recherche et prospective, 2008 ; réalisation : B. Lusso, 2013

Le bilan patrimonial du recyclage des friches industrielles du bassin minier du NordPas de Calais apparaît globalement mince par rapport à celui de la vallée de l'Emscher. En effet, l'ensemble des opérations de recyclage des friches minières menées dans la vallée de l'Emscher - et plus précisément dans le cadre de l'IBA Emscher Park - est particulièrement impressionnant. Ainsi, le parc paysager de la vallée de l'Emscher, d'une surface totale de $320 \mathrm{~km}^{2}$, a été constitué grâce à la réhabilitation de 93 sites différents. Les infrastructures industrielles ont été plus ou moins profondément réaménagées pour être adaptées à de nouveaux usages. De nombreux autres carreaux ont été partiellement préservés et reconvertis (Deshaies, 2007). D'autres ont été détruits. C'est le cas d'une immense aciérie de Gelsenkirchen entièrement démantelée il ne reste que le bâtiment administratif - pour faire place au parc scientifique de Rheinelbe. La conservation des sites n'a donc pas été une politique systématique dans la vallée de l'Emscher. Il s'agit plutôt de garder quelques sites remarquables inscrits depuis 1999 dans le cadre de la Route de l'héritage industriel (Route der Industriekultur). Autour des quatre grands sites emblématiques (gazomètre d'Oberhausen, Landschaftspark de Duisbourg Nord, complexes miniers Zollern et Zollverein), la Route de l'héritage industriel est composée de 52 sites industriels, dont seulement 11 sont strictement miniers. Fort de ce succès, le Land de Rhénanie du Nord-Westphalie a alors initié à partir de 2002 un projet de route européenne du patrimoine industriel. Il est donc indéniable que la vallée de l'Emscher dispose de plusieurs longueurs d'avance sur le bassin minier du Nord-Pas de Calais en matière de protection du patrimoine industriel. Néanmoins, dans les deux régions, celui-ci est l'objet d'ambitieuses opérations de réhabilitation. 


\section{Des principes de réhabilitation du patrimoine minier globalement similaires}

19 La démarche qui consiste à réutiliser le patrimoine industriel pour le sauvegarder est de plus en plus souvent empruntée dans l'optique de la requalification urbaine de quartiers ouvriers tombés en déshérence (Bianchini et Parkinson, 1993 ; Bailey et Stark, 2004 ; Miles et Paddison, 2005). L'héritage historique constitue alors l'image de marque du site ou du quartier requalifié, mais aussi un gage de qualité urbaine pour l'accueil de nouvelles activités. «Le renouveau s'appuie alors sur un passé revalorisé et pour ainsi dire recyclé" (Deshaies, 2007). La volonté d'urbanité précède donc le projet architectural (Lucchini, 2012). Toutefois, ces sites originellement industriels et patrimonialisés ne sont que très rarement adaptés à l'accueil des nouvelles activités culturelles auxquelles ils se destinent (Lusso, 2011). Pour ce faire, la prise en compte du patrimoine industriel doit être indirecte afin d'intégrer au mieux ces nouvelles fonctions (Edelblutte, 2008). Les lignes qui suivent visent donc à analyser les principales caractéristiques des opérations de régénération culturelle des sites industriels de la vallée de l'Emscher et du bassin minier du Nord-Pas de Calais mises en œuvre dans le cadre de politiques de reconversion du patrimoine industriel et de renversement de l'image de marque des territoires.

\section{Des choix architecturaux visant la mise en valeur du patrimoine minier}

Dans la vallée de l'Emscher comme pour le bassin minier du Nord-Pas de Calais, lorsque les infrastructures minières ne sont pas livrées aux démolisseurs, elles deviennent souvent le théâtre d'un grand projet (flagship project) d'équipement culturel. L'une des rares exceptions à cette règle est le Louvre-Lens, dont le bâtiment, une réalisation du cabinet d'architecture japonais SANAA, investit un ancien site minier complètement rasé. Un grand nombre de sites miniers de la vallée de l'Emscher ont donc accueilli tantôt un musée retraçant l'épopée industrielle de la Ruhr (mine Zollern à Dortmund) ou une salle de spectacle (gazomètre d'Oberhausen, Jahrhunderthalle de Bochum), tantôt un pôle de création artistique (complexe minier Zollverein à Essen). Quant aux quatre sites de mémoire du Nord-Pas de Calais, deux d'entre eux sont devenus des équipements culturels (musée de la mine sur l'ancienne fosse Delloye à Lewarde et salle de concert du Métaphone sur le site du 9/9 bis d'Oignies), alors que les deux autres abritent des lieux de création artistique (projet de pôle audiovisuel sur la mine de Wallers/Arenberg, friche théâtrale sur le 11/19 de Loos-en-Gohelle). Il s'agit donc principalement d'équipements culturels pouvant avoir un rayonnement métropolitain, national, voire international. Néanmoins, la création de grosses structures culturelles n'empêche pas le développement de projets de portée beaucoup plus locale comme le Kultur-Café installé dans l'ancienne mine Ickern à Castrop-Rauxel et le musée du Vieux 2 de Marles les Mines dans le Pas de Calais.

21 Si les principales caractéristiques architecturales des bâtiments préexistants sont soigneusement conservées, ces différents projets culturels cherchent aussi à développer une architecture iconique (Jencks, 2005) capable de marquer les esprits. C'est le cas de l'ancien lavoir de Hamm dans la Ruhr complètement réhabilité en 1984 sous la direction de l'architecte-artiste Horst Rellecke. Ce dernier a adjoint à la 
structure du lavoir un éléphant de verre géant. Ce nouvel équipement culturel qui accueille désormais un centre d'exposition et un jardin tropical ornementé de sculptures cinétiques, s'insère au cœur d'un vaste jardin public. Le succès de ce projet culturel qui attire chaque année plusieurs centaines de milliers de personnes, a inspiré les acteurs de l'IBA Emscher Park. En effet, pour assurer la réaffectation des friches industrielles à des fins culturelles, ces derniers ont privilégié des architectes (Norman Foster pour le complexe minier Zollverein) et des artistes contemporains de renom (Christo et Jeanne-Claude pour le gazomètre d'Oberhausen) illustrant ainsi parfaitement le néologisme de "starchitecture " (Gravari-Barbas, 2009). En raison de moyens financiers plus limités, les édiles du Nord-Pas de Calais ont opté pour des cabinets d'architectes et de paysagistes locaux reconnus dans la réhabilitation du patrimoine. Ainsi, la société Septentrionale Restauration Monuments Historiques a assuré la réhabilitation du site Arenberg financée par l'État, la Communauté d'Agglomération de la Porte du Hainaut, la ville de Wallers, la Région Nord-Pas de Calais et le Département du Nord.

Illustration 5 - Vue générale du carreau de la fosse Arenberg à Wallers

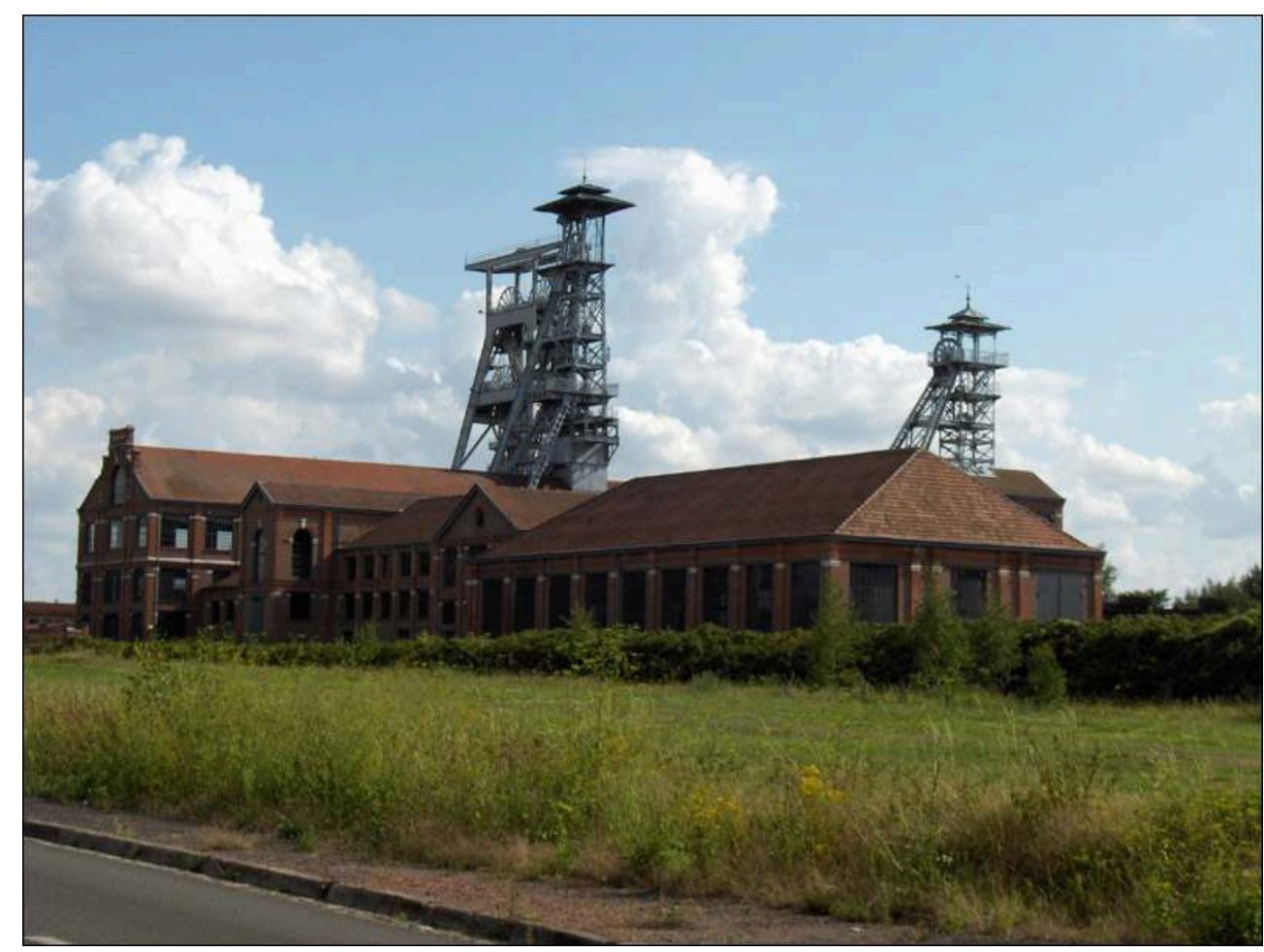

Auteur: B. Lusso, 2013.

Dans la mesure où la plupart de ces infrastructures minières font l'objet d'une protection patrimoniale, l'enjeu pour ces architectes et paysagistes est donc de réussir à reconstituer l'ambiance industrielle originelle. Ainsi, pour la réalisation du Musée du Design à Essen installé dans l'ancienne chaufferie du complexe minier Zollverein, les travaux de réhabilitation chapeautés par Norman Foster sont minimes. Les objets sont directement exposés dans la cavité des chaudières dénoyautées, au beau milieu d'anciennes tuyauteries, permettant de mieux rappeler la fonction initiale du site. Pour assurer la réhabilitation des fosses de Lewarde, d'Oignies, d'Arenberg et de Loos-en- 
Gohelle, seuls les matériaux ayant initialement servi à la construction de ces quatre sites de mémoire, ont été réutilisés.

Illustration 6 - Le site minier Zollverein, vue générale du Musée du Design Red Dot et de l'Ecole du Design

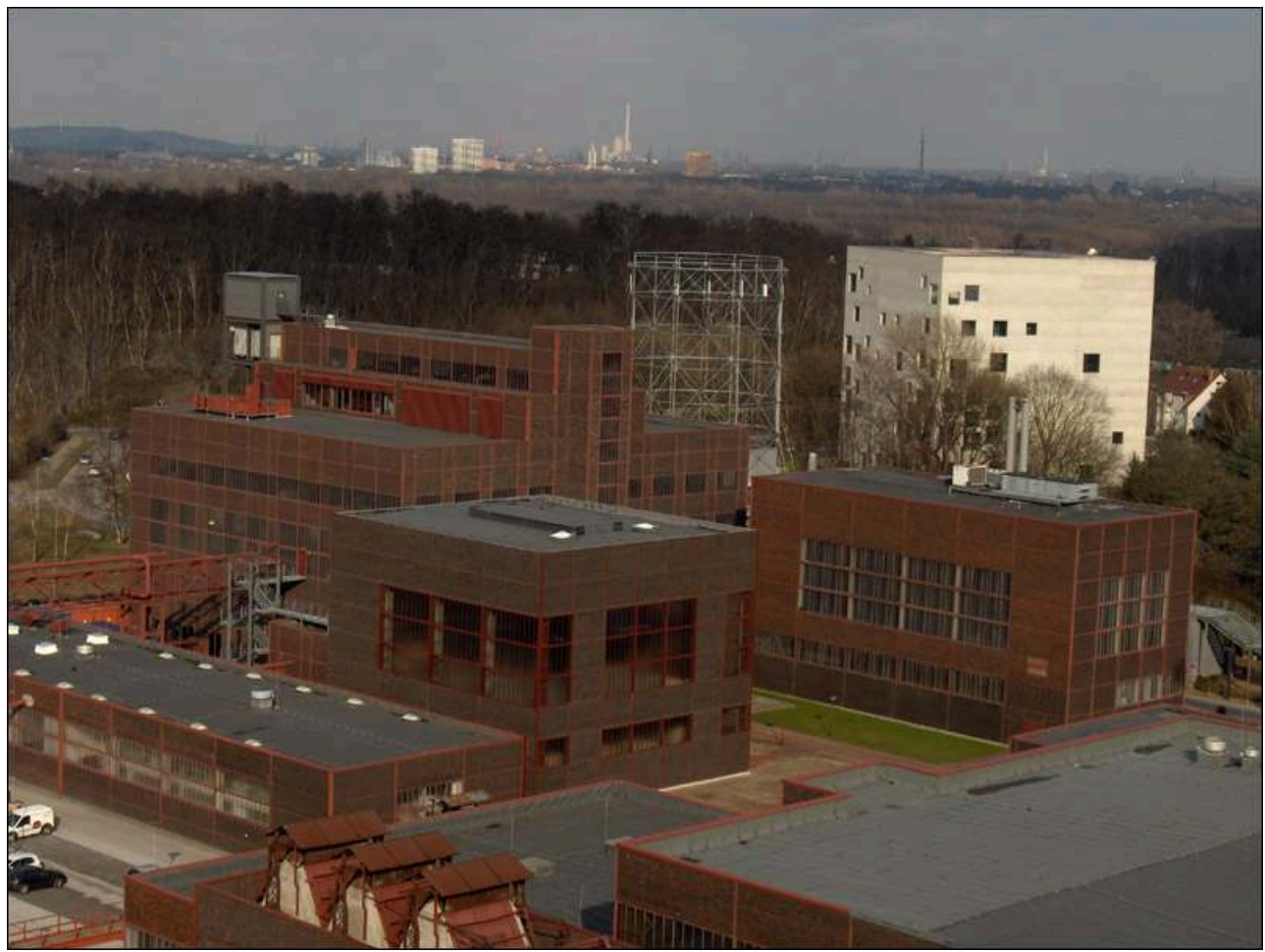

Auteur: B. Lusso, 2013. 
Illustration 7 - Galerie d'exposition du musée du Design Red Dot à Essen

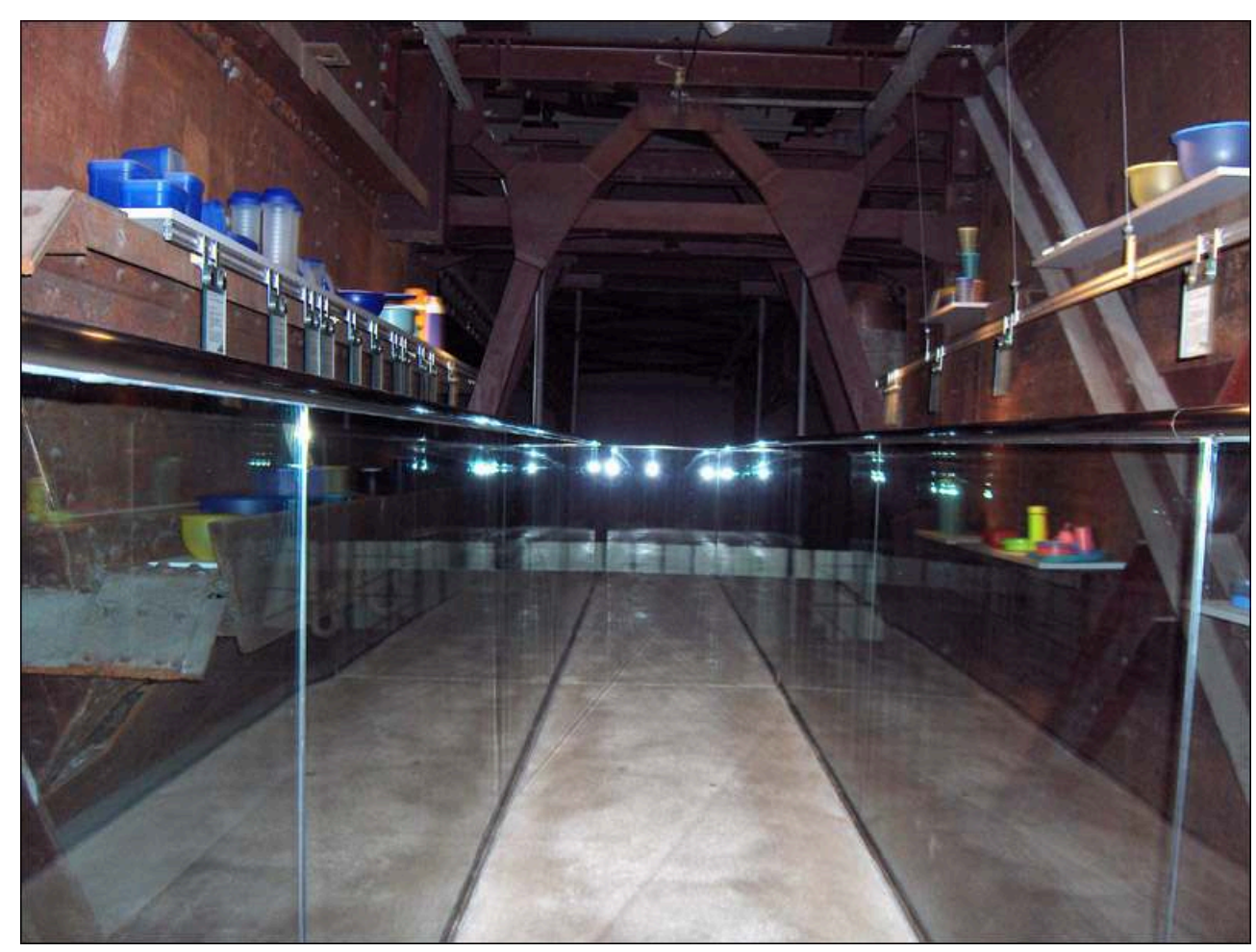

Auteur : B. Lusso, 2013.

De la même manière, quand une construction moderne est adjointe à l'ensemble minier, celle-ci adopte souvent un style architectural proche : ainsi, l'École du Design Zollverein réalisée par le cabinet SANAA est un hommage au style Bauhaus de la mine Zollverein. L'enjeu architectural est donc de créer un dialogue entre le nouveau et l'ancien à l'instar du Métaphone d'Oignies, une réalisation de l'agence Herauld Arnod Architectes qui investit le site de l'ancienne fosse $9 / 9$ bis des mines de Dourges. 
Illustration 7- La fosse 9/9 bis d'Oignies, vue générale du Métaphone et des infrastructures minières

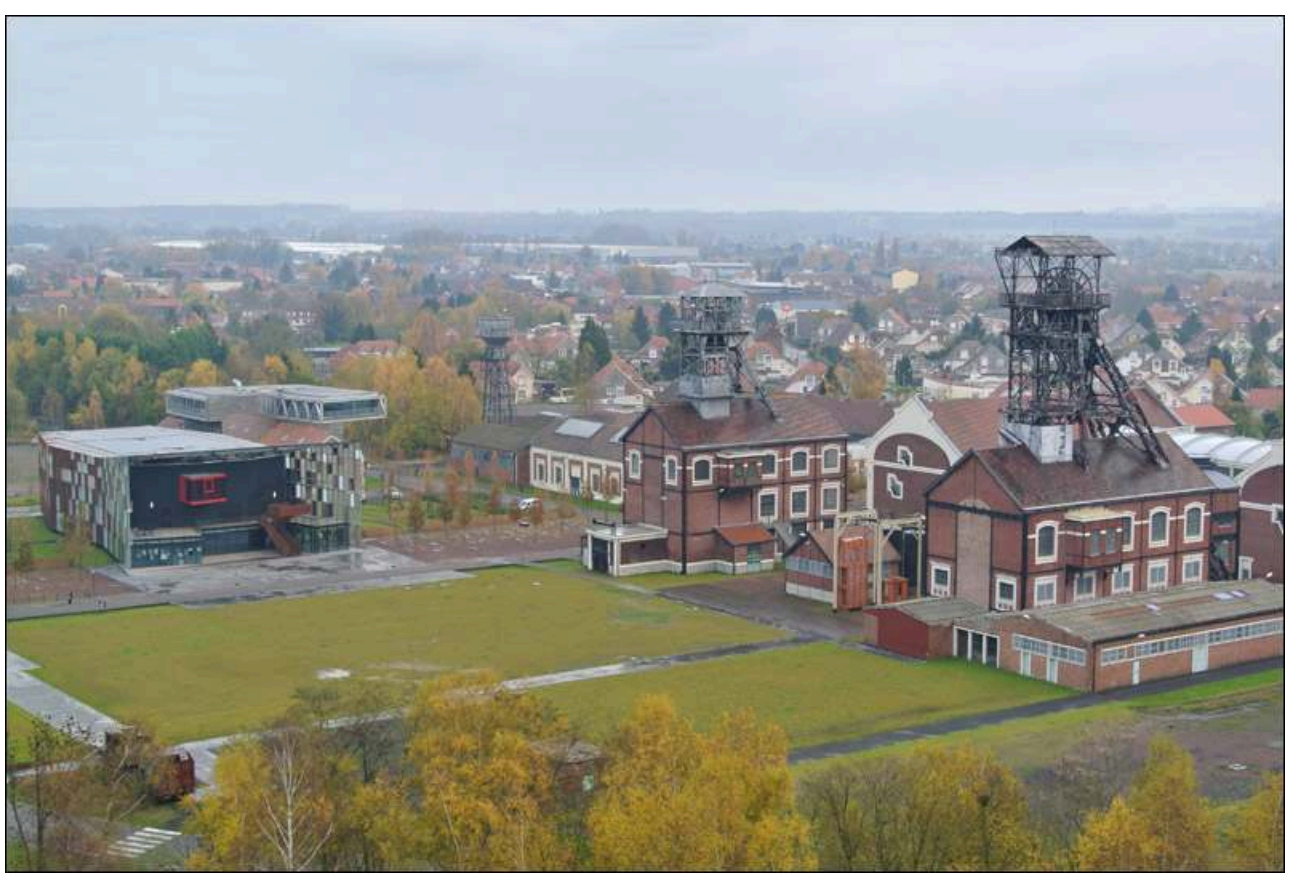

Auteur: B. Lusso, 2013.

Illustration 8 - Ancien atelier de la fosse $9 / 9$ bis d'Oignies et bureaux du Métaphone

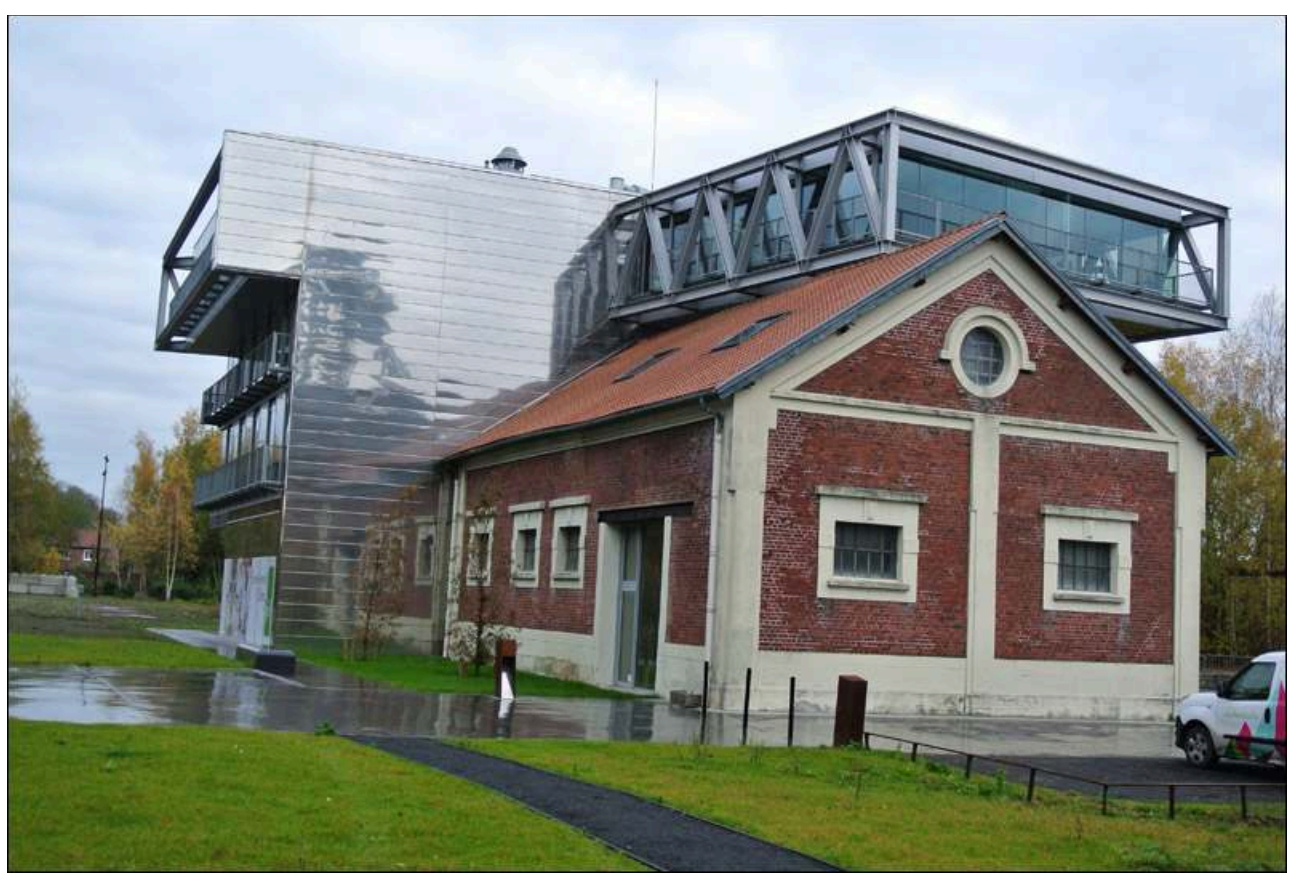

Auteur: B. Lusso, 2013.

24 Le volume et les couleurs (camaïeu de rouille et de bleus) du nouveau bâtiment qui s'ouvre sur une esplanade reliée à la salle des machines et aux chevalements, répond bien à la brique dominante des imposants bâtiments miniers. Pour assurer une continuité à l'ensemble, une greffe en inox est réalisée entre le bâtiment des bureaux 
du Métaphone et un ancien atelier de la fosse. Ce dialogue permet aussi de retracer l'évolution du site, de sa fonction originelle d'extraction à ses utilisations actuelle et future à des fins culturelles.

\section{Une inscription dans le cadre de vastes projets de régénération urbaine}

Dans les villes, les friches industrielles ont pour caractéristique de se localiser dans des quartiers périphériques parfois confrontés à de sérieux problèmes d'accessibilité et de pollution. Une telle situation a donc tendance à effrayer les investisseurs. Le contexte peu favorable, le relatif isolement et l'état potentiel de dégradation des bâtiments placent souvent les friches industrielles, mais aussi les secteurs urbains qui leur sont rattachés, en dehors du marché foncier (Bonneville, 2004). Si l'enjeu d'un équipement culturel est de réussir à renverser la tendance, celui-ci doit néanmoins s'inscrire dans un environnement agréable. De ce fait, il apparaît important de "redonner une lisibilité au lieu » (Barbier, 2002) afin que l'équipement soit appréhendé comme un lieu à part entière et non comme un élément nouveau mal intégré à un bâti urbain fortement dégradé. Pour ce faire, les cités minières sont rénovées. La voirie est refaite. Les trottoirs sont élargis et complantés d'arbres. Les fronts d'eau sont reconquis d'un point de vue écologique pour y développer des chemins de randonnée. Les terrils attenants aux anciens carreaux de mine revitalisés font l'objet d'un verdissement. De nouveaux signes urbains sont créés pour attirer le regard du visiteur. Dans la vallée de l'Emscher, là où "manquent" des "monuments trouvés ", l'IBA invite artistes et sculpteurs à la création de repères nouveaux (Lefèvre, 2000). Un tétraèdre, symbole de la transformation structurelle de la région, trône sur l'ancien terril de Bottrop. Une lampe de mineur géante créée par Otto Piene est installée sur le terril Rheinpreussen à Moers et rappelle avec fierté le passé industriel régional. Une sculpture de 15 mètres de haut conçue par Richard Serra se dresse tel un totem sur le terril de Schurenbach qui surplombe le vaste complexe minier Zollverein reconverti en pôle culturel et créatif. Ces symboles qui s'appuient sur l'identité du territoire et visibles à plusieurs kilomètres à la ronde, permettent de véhiculer une image forte et facilitent l'insertion territoriale de l'équipement culturel.

Ces politiques de réhabilitation visent autant à mettre en exergue l'identité industrielle de ces territoires qu'à recréer les centralités perdues de ces anciens "phares" de l'économie régionale (Soyez, 1999). C'est le cas dans la Ruhr du gazomètre d'Oberhausen situé sur un ancien site sidérurgique reconverti dès 1996 en centre d'exposition dédié aux nouvelles technologies. Ce dernier s'inscrit dans le cadre d'une vaste opération, Neue Mitte, qui vise à donner un centre urbain à la ville d'Oberhausen qui jusque-là en était quasiment dénuée. 
Illustration 9 - L'aménagement du Neue Mitte d'Oberhausen à partir de la réhabilitation du gazomètre transformé en centre d'exposition

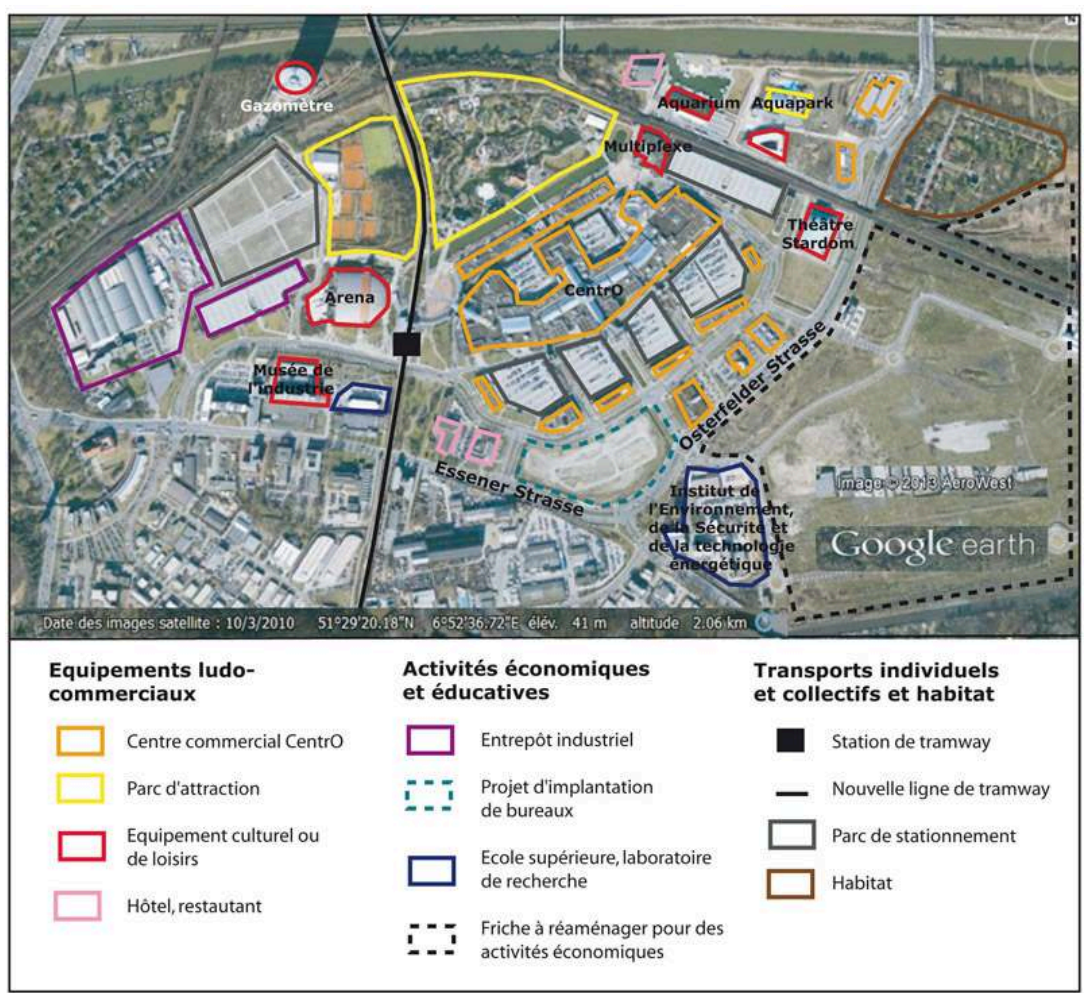

Source : Google Earth ; réalisation : B. Lusso, 2013.

Un complexe ludo-touristico-commercial baptisé CentrO s'est développé sur l'ancienne friche industrielle et comprend 200 magasins, un parc de loisirs, des restaurants, un complexe cinématographique, un théâtre, un parc d'activités, un port de plaisance et des espaces verts. Si cette opération urbaine contribue à la revitalisation économique du territoire, elle se fait souvent au détriment des centres urbains traditionnels de villes comme Essen ou Dortmund qui n'ont pas connu le même degré de transformation (Kurth, Scheuvens et Zlonicky, 1999).

Le choix d'un grand projet urbain s'explique aussi par les faibles retombées économiques et sociales d'un équipement culturel (Lusso, 2010) dans des régions industrielles marquées par une crise économique structurelle et un chômage massif. En effet, alors que le taux de chômage atteint les $23 \%$ dans le Douaisis, le Centre Historique Minier de Lewarde n'emploie que 90 personnes. Les équipements culturels ne génèrent donc pas beaucoup d'emplois et obligent les décideurs politiques à les inscrire dans le cadre de projets de régénération urbaine plus larges associant politiques en matière de transports, d'habitat, d'environnement et de développement économique (Werquin, 2008). C'est le cas du Métaphone de la fosse $9 / 9$ bis d'Oignies qui s'insère dans le cadre d'une vaste opération de régénération urbaine visant à développer un pôle économique et urbain. 
Illustration 10 - La reconversion culturelle et économique des carreaux des fosses $9 / 9$ bis et 10 à Oignies

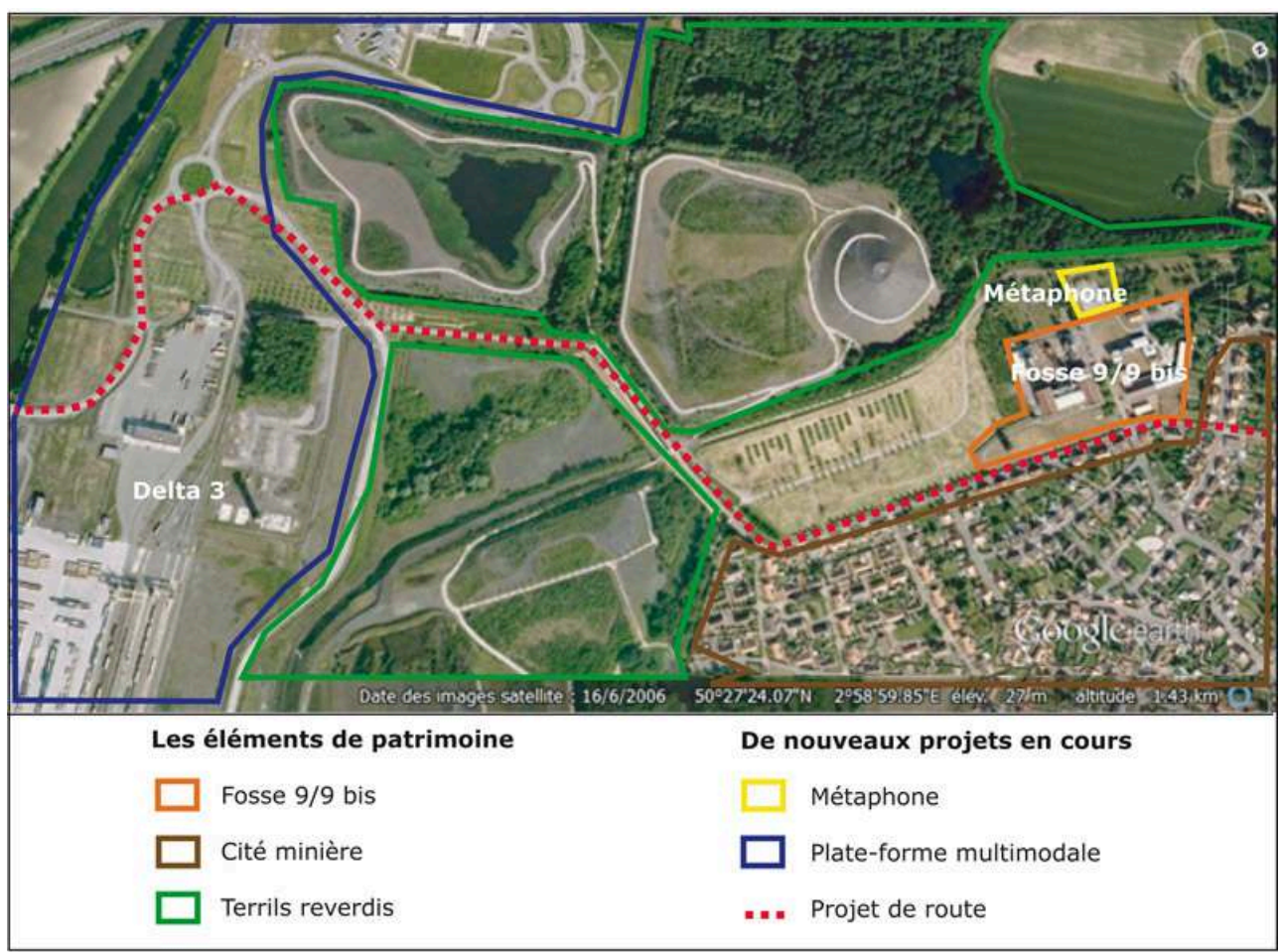

Source : Google Earth ; réalisation : B. Lusso, 2013.

Profitant de la proximité directe de la plate-forme multimodale de Dourges ouverte en 2004 sur l'ancien site de la fosse 10, la Communauté d'Agglomération Hénin-Carvin a décidé de valoriser l'espace inoccupé entre les deux sites pour créer une zone dédiée à la logistique comprenant des surfaces de bureaux et une école. Des aménagements sont envisagés pour favoriser le développement du tourisme d'affaires avec la construction d'un hôtel, de surfaces de restauration et de salles de séminaires. Enfin, un bâtiment tertiaire construit en 2008 devrait accueillir des bureaux ouverts à tous types d'activités. Afin de renforcer l'accessibilité de la future zone d'activités, une connexion avec le réseau autoroutier a été réalisée dès 2007 et un projet de raccordement du site minier au centre d'Oignies, finalisant la réinsertion du site dans la ville, est d'ores et déjà envisagé. Dans le cadre de la reconversion du site, les cités minières ont été réhabilitées, de nouveaux logements sont construits et l'ancien terril reconquis : ce dernier est en partie aménagé et ouvert au public sous la forme d'un espace vert, le reste étant consacré à la protection de la biodiversité.

\section{Le renversement de l'image en ligne de mire}

La régénération culturelle d'anciens sites miniers contribue donc à renverser l'image interne et externe (Gueit, 2005) de ces territoires anciennement industrialisés. Pourtant, la fréquentation de ces différents équipements culturels, largement dominée par les catégories socio-professionnelles les plus élevées et les groupes scolaires, n'explique pas cette nouvelle dynamique. En effet, les catégories sociales défavorisées représentent moins de $10 \%$ des publics du Centre Historique Minier de Lewarde, du Centre de la mine et du chemin de fer Denis Papin d'Oignies (ancienne fosse 2) ou du 
Musée du Design d'Essen. Seul le Louvre-Lens, dont l'accès à la galerie du Temps est entièrement gratuit, connaît une meilleure fréquentation populaire selon les édiles. Mais ce résultat reste à confirmer sur la durée. Ce sont finalement les premières mesures de protection du patrimoine minier qui ont encouragé la reconnaissance par les populations des qualités architecturales des infrastructures minières. Dans le bassin minier du Nord-Pas de Calais, des associations locales fleurissent et font la promotion d'un site minier. À la fosse de Wallers-Arenberg, Les Amis de Germinal proposent depuis 2000 des visites guidées du site minier, alors que le club Accusto Seci se bat dès 1993 pour faire de la fosse $9 / 9$ bis d'Oignies un centre de culture scientifique et technique.

31 L'action concertée des acteurs locaux a abouti à la protection au Patrimoine Mondial de l'Humanité d'un site - complexe minier Zollverein à Essen classé en 2001 - ou d'un ensemble de sites - 353 éléments répartis sur 109 sites classés en 2012 dans l'ancien bassin minier du Nord-Pas de Calais. Le classement du bassin minier du Nord-Pas de Calais au Patrimoine Mondial de l'Humanité au titre de Paysage Culturel Évolutif est le résultat d'un long cheminement et de l'implication des acteurs politiques régionaux. Dès 1997, Jean-François Caron, Maire de Loos-en-Gohelle et Conseiller régional, s'implique dans le dossier de l'après-mine. Celui-ci est rapidement soutenu par Pierre Mauroy, ancien Premier Ministre et Président de Lille Métropole Communauté Urbaine, et par Daniel Percheron, Président du Conseil Régional du Nord-Pas de Calais. Cette mobilisation des élus locaux et régionaux aboutit au lancement en 2003 de la Mission Bassin Minier Uni (BMU), dont l'objectif est d'instruire le dossier de candidature et d'organiser la mobilisation des populations dans la démarche de labellisation. Pour ce faire, des bénévoles lancent des Ateliers de BMU pour mener à bien ce projet de candidature. Des clubs sont mis en place par des établissements scolaires, des associations d'anciens mineurs ou des harmonies pour développer des rencontres événementielles. Les collectivités territoriales participent aussi à cet élan comme l'illustre le festival des « Rutilants » organisé sur le site du $9 / 9$ bis à Oignies et porté par la Communauté d'Agglomération Hénin-Carvin. Au travers de l'organisation de fanfares, de défilés de majorettes et de visites guidées de la mine, ce festival « unit culture, patrimoine historique bâti et patrimoine évolutif vivant en un seul tout permettant aux populations une meilleure reconnaissance et appropriation » (Bertram et Delmer, 2012). Le classement du bassin minier du Nord-Pas de Calais à l'UNESCO constitue donc l'aboutissement de ce long processus de reconnaissance et d'acceptation du patrimoine minier par les élus locaux et les populations.

Ce renversement de l'image interne du territoire constitue donc un préalable au développement de politiques de marketing urbain. Le classement du bassin minier du Nord-Pas de Calais a été largement relayé par les médias régionaux et nationaux. Les sites miniers de Lewarde, d'Oignies et de Wallers-Arenberg deviennent des sites touristiques incontournables apparaissant, au même titre que les beffrois ou la Bourse de Lille, dans les brochures éditées par les offices et agences de tourisme. Le bassin minier fait l'objet de livres touristiques proposant des panoramas et des vues sur les sites miniers. De l'image négative de "pays noir " à la fin des années 1980, le bassin minier du Nord-Pas de Calais est devenu au début des années 2010 une véritable destination touristique soutenue - il faut le reconnaître - par l'arrivée du Louvre à Lens. Quant à la vallée de l'Emscher, sa politique de reconversion culturelle des sites miniers a porté ses fruits. Sous le mot d'ordre « le changement grâce à la culture et la 
culture grâce au changement» («Wandel durch Kultur - Kultur durch Wandel »), les 53 communes de la Ruhr, fières de la transformation structurelle de leur région, ont posé leur candidature au titre de Capitale européenne de la culture pour l'année 2010. L'attribution de ce label a constitué un changement radical dans la perception du territoire qui a vu sa fréquentation hôtelière augmenter en 2011 de $4 \%$ suite à l'année culturelle, alors que la plupart des autres capitales européennes voient leurs recettes touristiques s'effriter après l'événement. Les friches culturelles ont donc bien joué un rôle clé dans le renversement de l'image interne et externe des deux territoires. Qu'en est-il de l'émergence d'une économie culturelle et créative?

\section{La réalité économique des greffes culturelles sur les friches industrielles}

En 2011, la Commission européenne a révélé que l'économie culturelle et créative représentait 3,3\% du PIB européen et 6,7 millions de salariés, soit $3 \%$ de l'emploi européen. Entre 2008 et 2011, l'emploi dans les domaines de la culture et de la création a été l'un des plus résistants à la crise économique (Commission européenne, 2012). Conscients des retombées des industries culturelles et créatives en termes d'image et de développement économique, de nombreux territoires cherchent à se spécialiser sur un créneau culturel ou une industrie créative (Gravari-Barbas et Violier, 2003). Toutefois, cette économie culturelle et créative est duale puisque :

- Certains chercheurs plaident pour une économie de la culture (Benhamou, 2000 ; Throsby, 2001; Hesmondhalgh, 2007), c'est-à-dire «un ensemble d'activités tournées vers l'exploitation marchande de la créativité artistique, esthétique et sémiotique " (Leriche, Daviet, Sibertin-Blanc et Zuliani, 2008). Cette première approche s'appuie davantage sur la valorisation économique des pratiques artistiques et du patrimoine dans leur relation avec les politiques culturelles qui génèrent des équipements moteurs.

- D'autres mettent en évidence une économie de la créativité (Hall, 2000 ; Florida, 2002 ; Cooke et Lazzeretti, 2008). Cette seconde approche étudie le développement des industries culturelles comme le cinéma, le livre ou la musique, mais intègre aussi des activités dont la finalité n'est pas uniquement culturelle comme la mode, le design ou la publicité.

L'analyse des modalités de développement de l'économie culturelle et créative dans les deux bassins miniers et les retombées territoriales de ces activités qui investissent majoritairement d'anciens sites miniers est donc au cœur de la dernière partie de cet article.

\section{Un nombre prédominant de musées dédiés à la culture industrielle et scientifique}

Les bassins miniers du Nord-Pas de Calais et de la vallée de l'Emscher sont marqués par un riche patrimoine matériel (fosses, lavoirs, cokeries, cités minières, documents d'archives, objets de travail du mineur...) et immatériel (fanfares, orchestres populaires, patois...) qu'il convient de conserver. C'est pourquoi les équipements culturels privilégiés par les aménageurs ont été des musées développant des thématiques de culture industrielle et scientifique. Dans le bassin minier du Nord-Pas de Calais, plusieurs petits musées thématiques consacrés à la mine et aux techniques industrielles ont fleuri sur les vestiges d'anciens carreaux de fosses à Auchel, à Bruay- 
la-Buissière, à Marles-les-Mines, à Noeux-les-Mines et à Oignies. Ceux-ci proposent donc une offre complémentaire à celle développée par le Centre Historique Minier de Lewarde. Mais leur petite taille les cantonne à un public local essentiellement constitué de groupes scolaires. Dans la vallée de l'Emscher, une dizaine de musées dédiés à l'histoire industrielle de la Ruhr ont investi de grands ensembles miniers désaffectés. Les thématiques sont très diversifiées, de l'histoire minière (musées de la mine Zollverein à Essen, Zollern à Dortmund, Hannover à Bochum, Nachtigal à Witten) à l'énergie (musée de l'électricité dans un ancien transformateur de Recklinghausen), en passant par les technologies de l'eau (musée de l'eau dans un ancien château d'eau de Mülheim an der Ruhr) ou l'industrie ferroviaire (musée du chemin de fer de BochumDalhausen sis dans un ancien entrepôt ferroviaire). Plus rares sont les musées consacrés aux Beaux-Arts (Louvre-Lens) ou au design (musée du design Red Dot à Essen). Il faut dire que les thématiques retenues pour ces musées sont principalement axées sur les sciences et les technologies. Cette discipline muséale qui s'appuie en grande partie sur les effets spéciaux et l'interactivité, connaît depuis les années 1980 un succès grandissant auprès du public (Lusso, 2009).

Il faut dire que ces musées s'insèrent dans le cadre de parcours touristiques et patrimoniaux plus larges, à l'instar de la Route de la culture industrielle dans la vallée de l'Emscher. Ces infrastructures reconverties à des fins culturelles et patrimoniales ont attiré en 2007 un peu plus de 2,4 millions de visiteurs, le pic ayant été enregistré en 2010, date de l'année culturelle. Ces chiffres très satisfaisants s'appuient notamment sur le succès des musées du design d'Essen et de la mine Zollern qui ont dépassé en 2010 le cap de 200000 visiteurs annuels. Dans le bassin minier du Nord-Pas de Calais, le Louvre-Lens, inauguré en décembre 2012, a attiré en un peu plus de dix mois 750000 visiteurs, dont une part croissante de visiteurs étrangers $(20 \%$ du total) principalement constituée de Belges, d'Allemands, de Néerlandais et de Britanniques. Si le Louvre-Lens est de très loin le musée le plus visité de la région Nord-Pas de Calais, le Centre Historique Minier de Lewarde se situe néanmoins à la quatrième place du classement régional avec un peu plus de 150000 visiteurs par an. Il est donc évident que les musées investissant d'anciennes friches minières jouent un rôle essentiel dans l'économie touristique régionale.

Pourtant, la fréquentation ne garantit pas l'équilibre financier des musées. En effet, les dépenses de fonctionnement du Louvre-Lens s'élèvent à 15 millions d'euros en année normale, alors que les recettes seraient estimées à 5 millions d'euros. De ce fait, le Conseil Régional devrait prendre en charge la majeure partie du budget de fonctionnement du Louvre-Lens. Cette situation est particulièrement inquiétante dans la vallée de l'Emscher où les musées sont confrontés à des difficultés financières. En effet, si l'IBA a réussi à lever des fonds d'investissement étatiques et européens pour la création de ces équipements culturels, la faiblesse des subventions de fonctionnement rend l'équilibre financier de ces structures extrêmement fragile, les condamnant à s'autogérer et à trouver de nouveaux modes de financement. Ainsi, malgré son transfert sur le site Zollverein en 2008, le Ruhrlandmuseum n'a pas su résorber son déficit financier. Le développement des activités commerciales (boutique, restaurant, librairie, accueil de colloques) pourrait être une solution (Benghozi et Bayart, 1993). Mais l'activité commerciale a ses propres limites, dans la mesure où elle génère, notamment en période de crise, des recettes très limitées. Ainsi, pour le Centre Historique Minier de Lewarde, $90 \%$ des ressources propres proviennent de la 
billetterie, alors que les activités commerciales ne représentent que $10 \%$ des recettes du musée. Le développement d'une programmation culturelle (expositions temporaires) et événementielle (défilés, parades, organisation de colloques) est une autre possibilité offerte aux musées pour trouver des ressources complémentaires. Toutefois, cela a aussi un coût élevé pour un résultat en termes de fréquentation très variable.

\section{Un recours croissant à la programmation événementielle}

La politique du grand projet (flagship) nécessite et s'appuie de plus en plus sur une programmation événementielle récurrente (festivals, plages, nuits blanches) ou exceptionnelle (capitale européenne de la culture, exposition internationale). En effet, les équipements culturels existent principalement au niveau national et international de par les grands événements qu'ils accueillent (Fagnoni, 2009). Les sites patrimoniaux sont investis par des médiations festives de plus en plus sophistiquées (mises en lumière, projection, théâtralisation) (Gravari-Barbas, 2009). C'est en ce sens qu'il faut comprendre l'éclairage du chevalement du Vieux II de Marles-les-Mines (bassin minier du Nord-Pas de Calais) récompensé en 1992 par un prix ou l'organisation depuis 1997 d'une exposition horticole annuelle sur le site minier Nordsternpark à Gelsenkirchen (Ruhr). De la même manière, de grandes expositions internationales sont organisées dans le gazomètre d'Oberhausen qui accueille chaque année plus de 450000 visiteurs, ou dans la salle des compresseurs de la cokerie Hansa à Dortmund.

En revanche, les organisateurs de festivals et d'événements culturels recherchent des lieux chargés de symboles. Si les sites miniers de la région Nord-Pas de Calais n'accueillaient jusqu'à présent que quelques manifestations culturelles (concerts en plein air sur le $9 / 9$ bis d'Oignies), la donne pourrait changer très rapidement avec l'ouverture en juin 2013 du Métaphone, une salle de concert bénéficiant d'une acoustique exceptionnelle, ou le projet de création d'une salle de spectacle rattachée à la Scène Nationale Culture Commune sur le site du 11/19 de Loos en Gohelle. Quant à la vallée de l'Emscher, d'anciennes friches minières ont été spécialement réhabilitées pour accueillir les activités événementielles organisées dans le cadre du KlavierFestival Ruhr, un festival de musique classique lancé en 1989, ou de l'emblématique Ruhrtriennale, un festival culturel organisé tous les trois ans depuis 2002 et financé par le Land de Rhénanie du Nord-Westphalie. Ces manifestations culturelles investissent des lieux chargés d'histoire comme une centrale électrique reconvertie en salle de spectacles, la Jahrhunderhalle de Bochum, ou un amphithéâtre en plein air de 800 places localisé au sommet du terril Haniel de Bochum.

Cette dynamique de festivalisation a atteint son paroxysme dans la vallée de l'Emscher avec l'organisation en 2010 de la Capitale européenne de la culture. Pour assurer l'organisation de l'événement, une société de droit privé, RUHR.2010 GmbH, a été créée et travaille en étroite collaboration avec la ville d'Essen, l'Association régionale de la Ruhr, le Land de Rhénanie du Nord-Westphalie et le Cercle d'Initiatives de la Région de la Ruhr (Initiativkreis Ruhrgebiet). Trois grandes thématiques " Urbanisme », "Identité » et "Intégration" ont été retenues et se sont articulées autour de quatre champs d'action « Ville des possibilités ", "Ville des arts », « Ville des cultures » et « Ville de la créativité ». L'année culturelle a donc été ponctuée de 5500 manifestations culturelles qui se sont appuyées sur un riche réseau de friches industrielles. Ainsi, 400 ballons 
jaunes ont été disposés à 80 mètres au-dessus des anciens puits de mine, rappelant à la fois l'exploitation minière et les changements structurels régionaux. Quant au festival Extraschicht organisé chaque année depuis 2001, il propose dans le cadre des installations industrielles de la Ruhr des mises en lumière, spectacles, concerts ou performances artistiques, et est devenu, grâce à sa fréquentation record en 2010 (200 000 visiteurs en une nuit), un temps fort de l'année culturelle. A Gelsenkirchen, le site minier Nordsternpark a accueilli la fête de clôture de l'année culturelle. Certains équipements ont été créés sur d'anciennes friches industrielles (centre d'art contemporain dans une ancienne brasserie de Dortmund), d'autres ont déménagé (musée de la Ruhr sur le complexe minier Zollverein) ou se sont agrandis (extension du musée d'art moderne et contemporain ouvert à Duisbourg en 1999 dans un ancien entrepôt du port intérieur). Plusieurs créations ont survécu, à l'instar du spectacle de danse urbaine Urbanatix, initialement présenté dans la Jahrhunderthalle de Bochum. Si l'année culturelle a attiré 10,5 millions de visiteurs et entraîné une hausse de $13 \%$ des nuitées, elle s'est révélée particulièrement chère pour les communes de la Ruhr. En effet, en raison d'une forte défection des sponsors et mécènes, le budget de l'année culturelle a été amputé de 20 millions d'euros pour atteindre cependant la coquette somme de 62,5 millions d'euros. Supporté en grande partie par les collectivités territoriales, il a contribué à creuser un peu plus le déficit financier structurel de certaines communes de la Ruhr. Néanmoins, l'événement a permis la mise en place d'un organisme de promotion de la Ruhr comme métropole culturelle qui a souligné l'importance du rôle des industries culturelles et créatives dans le développement des territoires.

\section{Un soutien accru aux industries culturelles et créatives}

41 De nombreux chercheurs pensent que la crise qui caractérise les villes et, à une échelle plus fine les friches industrielles, constitue aussi une période charnière annonçant un éventuel renouveau (Hall, 1998). Les processus de reconquête des friches industrielles, véritables stigmates physiques de la crise, grâce à la culture et aux pratiques artistiques, participeraient de ce mouvement. Dans certains de ces espaces dévitalisés, "l'après crise s'offre comme un temps de veille révélateur de leurs potentialités sociales et urbaines » (Andres et Ambrosino, 2008). Les fabriques artistiques, squats, art factories ou friches culturelles deviennent des lieux pouvant assurer le redéploiement économique d'espaces tombés en déshérence. Comme un grand nombre de friches dans les bassins miniers du Nord-Pas de Calais et de la Ruhr restent inoccupées en raison de leur situation périphérique dans des villes qui ne bénéficiaient pas à l'origine de lieux de diffusion culturelle, les pouvoirs publics ont donc encouragé l'installation d'artistes avec pour objectif de créer une émulation favorable à l'innovation artistique. C'est le cas dans la Ruhr de l'ancienne mine Ewald à Herten fermée en 2001 qui est notamment devenue une friche théâtrale occupée par la compagnie RevuePalast. Dans le bassin minier du Nord-Pas de Calais, le site du 11/19 accueille depuis sa réhabilitation en 1998 un écopôle, mais aussi une fabrique théâtrale gérée par la scène nationale Culture Commune créée en 1990 à l'initiative du Conseil général du Pas de Calais, de la Région Nord-Pas de Calais, de la DRAC Nord-Pas de Calais et de 27 communes du territoire pour stimuler localement une création contemporaine dans le domaine du spectacle vivant jusque-là quasi-inexistante. 
42 A la fin des années 1990, une nouvelle étape est franchie. En matière d'action publique, la planification de clusters culturels au sein de quartiers labellisés «culturels et créatifs", ou d'"industries culturelles", est devenue une "orthodoxie de l'aménagement et de la revitalisation urbaine » (Scott, 2004). Que ce soit dans la vallée de l'Emscher ou dans le bassin minier du Nord-Pas de Calais, les pouvoirs publics ont encouragé le développement des industries créatives ou culturelles sur les anciennes friches industrielles. C'est le cas de l'immense complexe minier Zollverein d'Essen, sur lequel est envisagée à la fin des années 1990 la création de toutes pièces d'une « ville du design ». Ainsi, une surface de $35000 \mathrm{~m}^{2}$ a été réservée dans l'environnement direct du musée du design ouvert en 1997 pour favoriser l'implantation d'entreprises, de logements et d'ateliers destinés aux jeunes créateurs dans le domaine des médias et du design. Le développement du site s'est poursuivi avec la création de la Zollverein School of Management and Design qui est aussi un laboratoire pour les arts, l'architecture et le design. L'école, ouverte en 2006, devait accueillir environ 600 étudiants et favoriser les passerelles entre le monde de la formation, de la recherche et les entreprises. Mais les prix d'inscription et de scolarité très élevés (1600 euros par an en moyenne) ont entraîné la fermeture rapide de l'école. Le site a été repris en 2010 par le département design de l'Université de Folkwang. Une extension du site est prévue, mais bute sur le financement que le Land de Rhénanie du Nord-Westphalie souhaite faire supporter par des investisseurs privés.

Illustration 11 - Le pôle culturel et créatif de Zollverein à Essen

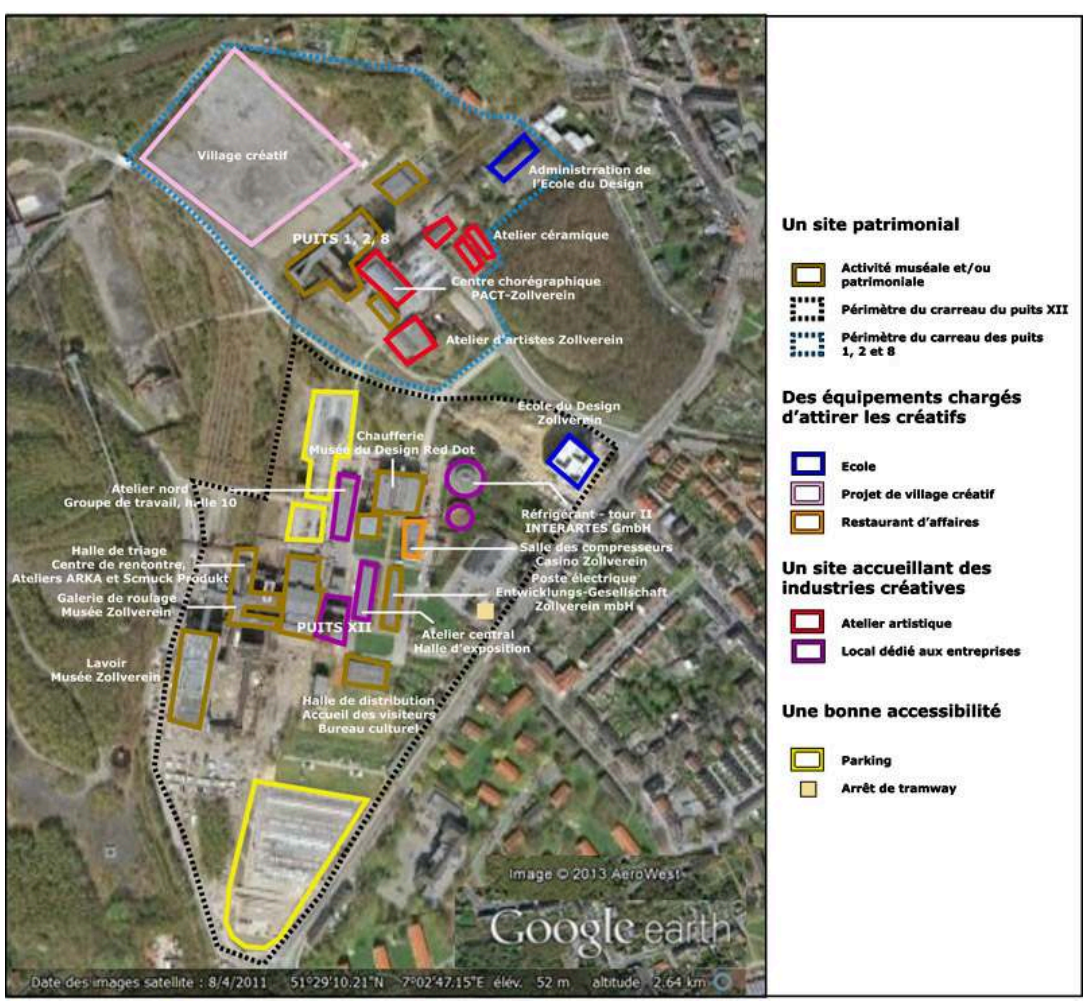

Source : Google Earth ; réalisation : B. Lusso, 2013.

43 D'un point de vue entrepreneurial, les pouvoirs publics espéraient l'implantation de 1300 bureaux de design à l'horizon 2010. Or, nous sommes assez loin de ces projections dans la mesure où seulement une vingtaine d'entreprises sont implantées sur le site. 
C'est le cas de la société Graf-Beyle spécialisée dans le film et le design d'animation qui réalise les décors pour quelques émissions de la chaîne culturelle franco-allemande Arte ou de la SARL Lichtdesign und Klangkonzept orientée vers le design lumineux et la conception sonore. Quant au projet de village créatif qui devait accueillir un hôtel, des bureaux et une résidence étudiante, celui-ci est resté depuis 2005 dans les cartons, en raison de négociations difficiles avec l'investisseur principal - le coût du projet est estimé à 140 millions d'euros - et de résultats en matière de développement économique de la «ville du design" plutôt mitigés. Si les activités liées au design génèrent depuis 2005 un chiffre d'affaires compris entre 300 et 400 millions d'euros, le site Zollverein conserve principalement une vocation touristique et patrimoniale (Lusso, 2010).

Conscient des résultats quelques peu décevants de la «cité du design », le Land de Rhénanie du Nord-Westphalie a lancé une réflexion autour du développement des industries créatives. Un groupe de réflexion sur la « ville de la créativité » est donc mis en place durant les travaux préparatoires à l'organisation de l'année culturelle. Celui-ci a souligné l'absence de stratégie régionale suffisamment claire dans le développement de l'économie créative. C'est pourquoi à l'initiative du Land de Rhénanie du NordWestphalie et de l'Association régionale de la Ruhr est créé en 2011 un Centre européen pour l'économie créative (Ecce) qui travaille en étroite collaboration avec les artistes, les créateurs, les municipalités, ainsi que les organismes de planification urbaine, économique et culturelle. Pour favoriser la concrétisation des différents projets créatifs, une agence de développement économique, la Wirtschaftsförderung Metropoleruhr $\mathrm{GmbH}$, voit le jour pour :

- Assurer la phase de développement économique des quartiers créatifs mis en place dans le cadre de la Capitale européenne de la culture (centre des arts, de l'éducation et de la créativité Dortmunder U dans l'ancienne brasserie de Dortmund, fabrique de jeux vidéo à Mülheim an der Ruhr) ;

- Soutenir l'essor de quartiers créatifs émergents (quartier créatif de Ruhrort à Duisbourg développé autour de la mode, du cinéma, de la télévision et des arts visuels) ;

- Identifier les secteurs potentiellement créatifs (quartier de Wiesenviertel à Witten qui dispose d'un grand nombre de cafés, équipements culturels et boîtes de nuit).

Conscient que ce type d'industrie repose principalement sur des phénomènes de réputation, le Centre européen pour l'économie créative a lancé dès sa création un magazine culturel numérique, le LABKULTUR.TV, qui constitue à la fois un outil de communication sur les dynamiques créatives locales et une plate-forme de réflexion européenne sur les logiques de développement de ces industries. Des partenariats sont donc établis avec le Forum d'Avignon, un réseau interactif constitué de représentants des secteurs de l'art, de la culture, de la politique, des sciences et des industries créatives, ou au sein de l'European Creative Business Network (ECBN). L'objectif du Centre européen pour l'économie créative est d'assurer la conversion économique de la Ruhr par le développement des industries créatives. Un enjeu très (peut-être trop) ambitieux... En effet, si l'économie culturelle et créative représente à l'échelle de la Ruhr 10000 entreprises et 86000 salariés, des voix commencent à s'élever au sein de l'Association régionale de la Ruhr et des instances politiques du Land de Rhénanie du Nord-Westphalie pour souligner le caractère particulièrement capitalistique de ces activités qui ne remplaceront jamais les emplois perdus dans l'industrie lourde. 
Ces réflexions touchent aussi les élus du bassin minier du Nord-Pas de Calais, et plus particulièrement ceux du Valenciennois qui ont misé dès les années 1980 sur le développement de l'industrie du multimédia pour assurer la conversion de l'aprèsmine. Ainsi, le Conseil Régional du Nord-Pas de Calais a confié à la Chambre de Commerce et d'Industrie du Valenciennois une mission numérique qui a abouti à la création de trois écoles, l'Institut Supérieur de Design (1987), l'école supérieure de cinéma d'animation Supinfocom (1988) et l'école de jeux vidéo Supinfogame (2002). Pour accompagner les jeunes diplômés de ces écoles, une pépinière d'entreprises, les Ateliers Numériques, a été créée en 2000. Si cette pépinière a accompagné depuis sa création une soixantaine de projets, aucun tissu créatif n'a réellement émergé. $90 \%$ des jeunes diplômés quittent le Valenciennois pour occuper un emploi dans la métropole lilloise, la région parisienne ou en Amérique du Nord. Si le recrutement international des trois écoles consulaires est un facteur explicatif, beaucoup d'étudiants reconnaissent que le Valenciennois n'offre pas suffisamment d'opportunités en matière d'emploi et de développement entrepreneurial (Lusso, 2011). Afin de retenir ces jeunes diplômés, la communauté d'agglomération de Valenciennes Métropole lance sur le site d'une ancienne aciérie d'Anzin le projet de Serre Numérique, un pôle multimédia devant accueillir à partir de 2014 un ensemble d'équipements visant à stimuler l'économie numérique locale.

Illustration 12 - Équipements constitutifs de la Serre Numérique d'Anzin et du Pôle de créativité numérique d'Arenberg

\begin{tabular}{|c|c|c|}
\hline Type d'équipements & Serre Numérique d'Anzin & $\begin{array}{l}\text { Pôle de créativité numérique } \\
\text { d'Arenberg }\end{array}$ \\
\hline Entreprises & $\begin{array}{l}\text { - Espace Entreprises comprenant } \\
\text { un incubateur, une pépinière et } \\
\text { un hôtel d'entreprises }\end{array}$ & $\begin{array}{l}\text { - Studios comprenant une salle de } \\
\text { tournage en milieu aquatique } \\
\text { - Surfaces de bureaux } \\
\text { - Résidence d'artistes }\end{array}$ \\
\hline $\begin{array}{l}\text { Ecoles et laboratoires } \\
\text { de recherche }\end{array}$ & $\begin{array}{l}\text { - Supinfocom (animation) } \\
\text { - Supinfogame (jeu vidéo) } \\
\text { - Institut Supérieur de Design } \\
\text { - Centre de recherche et de } \\
\text { transfert de technologie }\end{array}$ & $\begin{array}{l}\text { - Laboratoire des Sciences de la } \\
\text { Communication (LSC) de l'Université de } \\
\text { Valenciennes et du Hainaut-Cambrésis } \\
\text { - Centre de formation continue }\end{array}$ \\
\hline $\begin{array}{l}\text { Equipements } \\
\text { techniques et } \\
\text { structures sociales }\end{array}$ & $\begin{array}{l}\text { - Espace immersif de réalité } \\
\text { virtuelle } \\
\text { - Espace de coworking } \\
\text { - Learning center dédié à la } \\
\text { création numérique } \\
\text { Salle d'accueil de } \\
\text { manifestations } \\
\text { - Restaurant } \\
\text { - Espace de détente } \\
\text { - Logements }\end{array}$ & $\begin{array}{l}\text { - Salle de projection de } 300 \text { places } \\
\text { - Salle d'exposition } \\
\text { - Cinémathèque } \\
\text { - Pôle touristique avec parc urbain et } \\
\text { parcours minier }\end{array}$ \\
\hline
\end{tabular}

Auteur : B. Lusso, 2013. 
Si la Serre Numérique se situe en périphérie de la zone d'activités des Tertiales localisée à proximité directe du centre de Valenciennes, un deuxième projet a pourtant été lancé par une collectivité voisine, la Communauté d'agglomération de la Porte du Hainaut. Ainsi, un pôle de créativité numérique devrait émerger d'ici 2020 sur le site d'un ancien carreau de fosse localisé à moins de 10 kilomètres de la future Serre Numérique, au cœur d'une cité issue des charbonnages d'Arenberg et isolé des grands équipements métropolitains. Quel est l'argument pour implanter ce pôle de créativité numérique ? Depuis une vingtaine d'années, la mine d'Arenberg a été le décor occasionnel de plusieurs films. Si les deux projets de pôle numérique dans le Valenciennois intègrent la stratégie développée par Pictanovo, la structure chargée d'animer l'industrie du multimédia en région Nord-Pas de Calais, il apparaît néanmoins très difficile de croire en la réussite totale de cette greffe culturelle sur l'ancien site minier d'Arenberg.

\section{Conclusion}

L'analyse comparée des politiques de recyclage des sites industriels et charbonniers dans le bassin minier du Nord-Pas de Calais et la vallée de l'Emscher a démontré que la protection des friches minières a été beaucoup plus poussée dans la vallée de l'Emscher que dans le Nord-Pas de Calais. Toutefois, ces différences s'expliquent beaucoup moins par le rapport à l'héritage industriel que par des contextes économiques et territoriaux radicalement distincts. Certes, la prise en compte du patrimoine minier dans le NordPas de Calais a été plus tardive. Mais il faut aussi reconnaitre que la crise industrielle a été beaucoup plus forte et violente dans la région Nord-Pas de Calais - qui a connu l'effondrement de plusieurs fleurons de son industrie - que dans la Ruh restée à ce jour un territoire économiquement dynamique. Les priorités n'étaient donc pas les mêmes : si les élus de la vallée de l'Emscher pouvaient mener des politiques en faveur du cadre de vie, la situation économique alarmante de la région Nord-Pas de Calais a poussé l'État à mettre en œuvre des politiques de reconversion qui ne prenaient pas en compte la question du patrimoine minier. Les échelles d'intervention territoriale de ces politiques - ensemble de la région Nord-Pas de Calais versus la vallée de l'Emscher, un secteur de la Ruhr - ne sont pas les mêmes. Il en résulte donc des financements moindres pour les élus du Nord-Pas de Calais dans le recyclage et la patrimonialisation des friches minières. La mort dans l'âme, certains d'entre eux ont été contraints à la politique de la table rase.

Malgré tout, des sites miniers ont été conservés dans les deux bassins miniers et font désormais l'objet d'ambitieuses politiques de réhabilitation. Dans la vallée de l'Emscher tout comme dans le bassin minier du Nord-Pas de Calais, la régénération culturelle des friches minières s'est inscrite dans le cadre de vastes opérations urbaines qui visent à faire de ces anciens sites industriels de véritables centralités urbaines. C'est pourquoi la réhabilitation des bâtiments a été confiée à des architectes et à des paysagistes de renom qui ont souvent opté pour une restructuration discrète (mais certaine) et conforme aux caractéristiques architecturales du site. Cette politique de recyclage a porté ses fruits. Le patrimoine minier a fait progressivement l'objet d'une appropriation par les populations et les élus régionaux qui ont œuvré en faveur de sa reconnaissance nationale et internationale. L'organisation de la Capitale européenne dans la Ruhr et le classement du bassin minier du Nord-Pas de Calais au Patrimoine 
Mondial de l'Humanité traduisent la réussite de ces politiques de régénération culturelle en termes d'image et de marketing urbain.

Enfin, les deux bassins miniers de la Ruhr et du Nord-Pas de Calais ont misé sur le développement de l'économie culturelle et créative. De nombreux musées dédiés à la culture industrielle ont vu le jour mais leur fragile bilan économique a poussé les édiles à investir dans le développement d'événements culturels ponctuels ou structurels, ainsi que dans les industries culturelles et créatives. En dépit d'ambitieux projets économiques, le bilan en termes de création d'emplois et de valeur apparaitt très mitigé, alors que ces industries culturelles et créatives sont particulièrement gourmandes en capitaux et en investissement. Le financement de telles activités se pose alors que de nombreuses villes de la Ruhr se trouvent dans une situation très délicate de surendettement. Celles-ci sont désormais contraintes de pousser leurs musées et équipements culturels récemment créés sur d'anciennes friches industrielles à s'autogérer mettant ainsi en danger leur pérennisation. Les entreprises du secteur créatif ne peuvent désormais compter que sur l'apport financier d'investisseurs privés providentiels. Quant au Conseil Régional du Nord-Pas de Calais, principal financeur des activités culturelles et créatives, il est contraint à des coupes drastiques dans son budget pour pouvoir continuer à sanctuariser les aides apportées au secteur. La question d'un financement privé de plus en plus conséquent de ces activités est donc posée.

\section{BIBLIOGRAPHIE}

Andres L., Ambrosino C., 2008. Régénération culturelle et mutabilité urbaine : un regard francobritannique. In Leriche F., Daviet S., Sibertin-Blanc M., Zuliani J-M., L'économie culturelle et ses territoires. Toulouse, Presses Universitaires du Mirail, coll. Villes et Territoires, p. 305-316.

Andrieux J.-Y., 1992. Le patrimoine industriel. Paris, Presses Universitaires de France, coll. Que saisje ?, n² 2657, $127 \mathrm{p}$.

Bailey C., Miles S., Stark P., 2004. Culture-led urban regeneration and the revitalization of identities. Newcastle, Gateshead and the North East of England. International Journal of Cultural Policy, vol. 10-1, p. 47-65.

Barbier K., 2002. L'impact culturel des friches industrielles. Lille, Mémoire de DEA, 128 p.

Baudelle G., 1995. Le système spatial de la mine, l'exemple du bassin houiller du Nord-Pas de Calais. Lille, Thèse de doctorat d'État ès lettres, $1228 \mathrm{p}$.

Becher B., Becher H., 1970. Anonyme Skulpturen. Ein Typologie technischer Bauten. Düsseldorf, Art Press, $208 \mathrm{p}$.

Becher B., Becher H., 1985. Födertürme. München, Schirmer/Mosel Publishing, 220 p.

Belhoste J.-F., Smith P. (dir.), 1997. Patrimoine industriel, 50 sites en France. Paris, Éditions du patrimoine, $128 \mathrm{p}$. 
Benghozi P-J., Bayart D., 1993. Le tournant commercial des musées en France et à l'étranger. Paris, La Documentation Française, 295 p.

Benhamou F., 2000. L'économie de la culture. Paris, éditions de La Découverte, 126 p.

Bertram C., Delmer S., 2012. De la fosse minière au métaphone : la conversion du site 9/9bis en grand projet de territoire et élément exceptionnel de la candidature du bassin minier Nord-Pas de Calais à l'UNESCO en tant que Paysage culturel évolutif. Colloque international pluridisciplinaire. De la friche industrielle au lieu culturel, Rouen, 14 juin 2012, p. 231-239.

Bianchini F., Parkinson M. (dir.), 1993. Cultural Policy and Urban Regeneration. The West European Experience. Manchester and New York, Manchester University Press, $282 \mathrm{p}$.

Bonneville M., 2004. Les ambiguïtés du renouvellement urbain en France. Les Annales de la Recherche Urbaine, $\mathrm{n}^{\circ}$ 97, p. 7-15.

Commission européenne, 2012. Promouvoir les secteurs de la culture et de la création pour favoriser la croissance de l'emploi dans l'Union européenne. Communication de la Commission au Parlement européen, au Conseil, au Comité économique et social européen et au Comité des régions, Bruxelles, $15 \mathrm{p}$.

Cooke P., Lazzeretti L., 2008. Creative cities, cultural clusters and local economic development. Cheltenham UK, Edward Elgar Publishing, 384 p.

Daumas M., 1980. L'archéologie industrielle en France. Paris, Robert Laffont, 463 p.

De Roux E., 2000. Patrimoine industriel. Paris, Scala, 271 p.

Delony E., 1992. Landmark American Bridges. New York, American Society of Civil Engineers, 153 p. Deshaies M., 2007. Les territoires miniers, exploitation et reconquête. Paris, Ellipses, 224 p.

Edelblutte S., 2008. Paysages et territoires du patrimoine industriel au Royaume-Uni. Revue Géographique de l'Est, vol. 48, 1-2.

Ernecq J-M., 1998. Préface. In Plan Urbain, Ministère de l'Equipement, Les villes européennes de tradition industrielle. Mutations économiques et politiques urbaines. Lille, Presses Universitaires de Lille, coll. Économies et sociétés, p. 13-18.

Fagnoni E., 2009. Culture décentralisée et innovation urbaine. Metz et le Centre Pompidou. In Lemasson J-P, Violier P. (dir.), Destinations et territoires, vol. 1 Coprésence à l'œuvre. Québec, Téoros/ Presses de l'Université du Québec, p. 206-219.

Florida R., 2002. The rise of the creative class. New York, Basic Books, $434 \mathrm{p}$.

Ganser K., 1996. Die Internationale Bauaustellung Emscher Park : Struckturpolitik für Industrieregionen. Bochumer AG, n 58, p. 189-196.

Gravari-Barbas M., Violier P. (dir.), 2003. Lieux de culture, culture des lieux. Rennes, PUR, 300 p.

Gravari-Barbas M. (dir.), 2005. Habiter le patrimoine: enjeux, approches, vécu. Rennes, PUR, 618 p.

Gravari-Barbas, 2009. « Marques d'architecte », « Marque de musée », l'architecture médiatique en tant qu'outil de positionnement touristique urbain. In Lemasson J-P, Violier P. (dir.), Destinations et territoires : coprésence à l'œuvre. Québec, Téoros/Presses de l'Université du Québec, p. $190-205$.

Gueit J., 2005. La culture, moteur de réparation et d'une nouvelle image des villes industrielles : le LouvreLens. Lille, Mémoire de master, 168 p. 
Güthling M., 2009. Innerstädtische Brachflächen - Untersuchungen zur Umgestaltung von innerstädtischen Bahnflächen am Beispiel des Reichsbahnausbesserungswerkes Potsdam. Heft, Arbeitshefte des Instituts für Stadt- und Regionalplanung der TU Berlin, 74 p.

Hall P., 1998. Cities in Civilization. New York, Pantheon Books, 1184 p.

Hall P., 2000. Creative cities and economic development. Urban Studies, $\mathrm{n}^{\circ}$ 37-4, p. 639-649.

Harvey D., 1989. The urban experience. Baltimore, Johns Hopkins University Press, 312 p.

Hesmondhalgh D., 2007. The cultural industries. London, Sage publications, $480 \mathrm{p}$.

Holz J.-M., 1988. La Ruhr, crise, reconversion et dynamique régionale. Metz, Thèse de doctorat d'Etat ès lettres, 3 vol., $1410 \mathrm{p}$.

Hudson R., Sadler D., 1989. The International Steel Industry: Restructuring, state policies and localities. London, Routledge, $192 \mathrm{p}$.

Ingallina P., Park J., 2005. Les nouveaux enjeux de l'attractivité urbaine. Urbanisme, $\mathrm{n}^{\circ} 344$, p. 66-68.

Jencks C., 2005. The iconic building: the power of enigma. New York, Rizzoli, 192 p.

Joly N., 2001. Les territoires renouvelés de l'après-charbon. Lille, Thèse de doctorat, 2 vol., 512 p.

Krins H., Goer M. Schmidt L., 1991. Brücke, Mühle und Fabrik. Technische Kulturdenkmale in BadenWürttember. Stuttgart, Verlag Theiss, $230 \mathrm{p}$.

Kunzmann K-R., 1996. Schöne weisse Arbeitselefenten in Zukunfsplatz. Topos, Landscape European Magazine, np.

Kurth D., Scheuvens R., Zlonicky P., 1999. Laboratorium Emscher Park, Städtebauliches Kolloquium zur Zukunft des Ruhrgebietes. Dortmund, Informationskreis f. Raumplanung, 175 p.

Leboutte R., 1997. Vie et mort des bassins industriels en Europe. 1750-2000. Paris, L'Harmattan, 591 p.

Lefevre P., 2000. L'art du paysage à Emscher Park. Les Annales de la recherche urbaine, $\mathrm{n}^{\circ}$ 85, p. 190-195.

Leriche F., Daviet S., Sibertin-Blanc M., Zuliani J-M., 2008. L'économie culturelle et ses territoires. Toulouse, Presses Universitaires du Mirail, coll. Villes et Territoires, 381 p.

Lucchini F., 2012. La fabrique des lieux : réapproprier des lieux par la culture. Colloque international pluridisciplinaire. De la friche industrielle au lieu culturel. Rouen, 14 juin 2012, p. 9-21.

Lusso B., 2008. Les politiques culturelles à Roubaix, à la croisée de l'urbain et du social. Culture et gouvernance locale, vol. $1, \mathrm{n}^{\circ} 1, \mathrm{p} .79-91$.

Lusso B., 2009. Les musées, un outil efficace de régénération urbaine ? Les exemples de Mons (Belgique), Essen (Allemagne) et Manchester (Royaume-Uni). Cybergéo, Espace, Société, Territoire, article 436

Lusso B., 2010. Culture et régénération urbaine : les exemples de la vallée de l'Emscher et du Grand Manchester. Métropoles, $\mathrm{n}^{\circ}$ 8-2010.

Lusso B., 2011. Les dynamiques territoriales du secteur de l'image en mouvement dans les aires métropolitaines de Lille, de Lyon et de Marseille. Lille, Thèse de doctorat, 410 p.

Masboungi A. (dir.), 2000. L'IBA Emscher Park, un anti-modèle. Projet urbain, $\mathrm{n}^{\circ} 21$, Direction Générale de l'Urbanisme, de l'Habitat et de la Construction, 27 p. 
Miles S., Paddison R., 2005. Introduction: the rise of culture-led urban regeneration. Urban Studies, vol. 42, $\mathrm{n}^{\circ}$ 5-6, p. 833-839.

Militz C. Rudolph W., 1984. Spuren im Wer. Heidelberg, Braus, 96 p.

Oevermann H., 2012. Über den Umgang mit dem industriellen Erbe. Eine diskursanalytische Untersuchung städtischer Transformationsprozesse am Beispiel der Zeche Zollverein. Essen, KlartextVerlag, $290 \mathrm{p}$.

Schwarz A. (dir.), 2001. Vom Industriebetrieb zum Landschaftspark. Essen, Klartext-Verlag, 208 p.

Scott A.J., 2000. The cultural economy of cities. London, Sage publications, 256 p.

Scott A.-J., 2004. Cultural-Products Industries and urban Economic Development: prospects for growth and market contestation in a global context. Urban Affairs Review, $n^{\circ} 39-4$, p. 461-490.

Soyez D., 1999. Le patrimoine industriel des régions d'industrialisation ancienne. Textes Géographiques Virtuels sur le Canada et l'Allemagne http://www.v-g-t.de/francais/brd/module/m2/ u9.htm

Throsby D., 2001. Economics and culture. Cambridge, Cambridge University Press, 228 p.

Van der Borg J., Costa P., Gotti G., 1996. Tourism in European heritage cities. Annals of Tourism Research, $\mathrm{n}^{\circ} 23$.

Werquin T., 2008. L'impact des équipements et évènements culturels sur le développement économique local : entre fantasme et réalité. Actes du colloque du 6 et 7 mai 2008 Arts et Territoires : vers une nouvelle économie culturelle? Québec, 6 et 7 mai 2008, np.

\section{RÉSUMÉS}

À partir de la confrontation des expériences menées dans les bassins charbonniers du Nord-Pas de Calais et de la Ruhr, l'objectif de cet article est d'analyser les modalités de la transformation des infrastructures minières en lieux culturels. Si dans la Ruhr les populations et les villes se sont très rapidement réappropriées ces anciens "phares " de l'économie régionale, les collectivités territoriales de l'ex-bassin minier du Nord-Pas de Calais ont en revanche largement détruit leurs friches industrielles. Toutefois, un changement dans la perception du patrimoine industriel s'est effectué à partir de la fin des années 1980. Diverses mesures ont favorisé la réhabilitation et la patrimonialisation de ces friches minières dans le cadre de vastes périmètres de régénération urbaine. Ces infrastructures abritent désormais des équipements culturels, des activités créatives et, le cas échéant, des festivals.

From the confrontation of the experiences implemented in the Nord-Pas de Calais and the Ruhr coalfields, the aim of this paper is to analyze the transformation of coal pits in cultural places. In the Ruhr area, populations and cities themselves re-appropriated very quickly these old "flagships" of the regional economy. In the Nord-Pas de Calais, public authorities have rather dismantle the derelict lands. However, political philosophy has changed since the end of the 1980s, making possible the cultural regeneration of some wastelands inherited from mining industry throughout new cultural facilities, creative industries and festivals. 
INDEX

Keywords : Derelict land, cultural regeneration, inheritage, creativity, old manufacturing region Mots-clés : Friche industrielle, régénération culturelle, patrimoine, créativité, vieille région industrielle

\section{AUTEUR}

\section{BRUNO LUSSO}

Bruno Lusso, blusso@cegetel.net, est Docteur en Géographie et Aménagement, Chercheur postdoctoral, UFR de Géographie et Aménagement de l'Université de Lille 1. Il a publié récemment :

- Lusso B., 2010. Culture et régénération urbaine : les exemples de la vallée de l'Emscher et du Grand Manchester. Métropoles, 8-2010.

- Lusso B., 2009. Les musées, un outil efficace de régénération urbaine ? Les exemples de Mons (Belgique), Essen (Allemagne) et Manchester (Royaume-Uni). Cybergéo, Espace, Société, Territoire, article 436.

- Lusso B., 2008. Les politiques culturelles à Roubaix, à la croisée de l'urbain et du social. Culture et gouvernance locale, vol. $1 \mathrm{n}^{\circ} 1$, p. 79-91. 